\section{ANEMIAS RARAS Y FALLOS MEDULARES HEREDITARIOS}

Joan-Lluis Vives Corrons

Instituto de Investigación contra la Leucemia Josep Carreras Hospital Clínic. Universidad de Barcelona ORCID iD: https://orcid.org/orcid.org/0000-0003-1820-2594 jlvives@ub.es

Maria del Mar Mañú Pereira Instituto de Investigación Vall d'Hebron. Hospital Universitario Vall d'Hebron ORCID iD: https://orcid.org/0000-0003-4770-7460 mar.manu@vhir.org

Juan Pablo Trujillo Universidad Autónoma de Barcelona / Centro de Investigación Biomédica en Red de Enfermedades Raras (CIBERER) ORCID iD: https://orcid.org/0000-0001-5901-9388 jtrujyq@gmail.com

Jordi Surrallés

Universidad Autónoma de Barcelona / Centro de Investigación Biomédica en Red de Enfermedades Raras (CIBERER) ORCID iD: https://orcid.org/0000-0002-4041-7519

Jordi.surralles@uab.es

Julián Sevilla

Hospital Infantil Universitario Niño Jesús ORCID iD: https://orcid.org/0000-0002-6852-1860 julian.sevilla@salud.madrid.org

Cómo citar este artículo/Citation: Vives Corrons, J. L., Mañú Pereira, M. M., Trujillo, J. P., Surrallés, J. y Sevilla, J. (2018). Anemias raras y fallos medulares hereditarios. Arbor, 194 (789): a463. https://doi.org/10.3989/arbor.2018.789n3005

Recibido: 30 abril 2015. Aceptado: 13 mayo 2016.

RESUMEN: Las anemias raras y los fallos medulares hereditarios son enfermedades hematológicas caracterizadas, respectivamente, por una disminución de la concentración de hemoglobina o por diversos grados de defectos en la producción de células hematopoyéticas que conducen desde una citopenia de un solo linaje hasta una de múltiples linajes. Son enfermedades raras y difíciles de diagnosticar debido a la heterogeneidad clínica, citológica y genética. En este artículo abordaremos en primer lugar el diagnóstico de las anemias raras y sus causas principales: fallos medulares, defectos del hematíe y trastornos del metabolismo de los factores de maduración eritrocitario. Seguidamente introduciremos los fallos medulares hereditarios y su patología asociada, como son las malformaciones congénitas y la predisposición tumoral, haciendo especial hincapié en los más frecuentes: la anemia de Fanconi, la disqueratosis congénitca, la anemia de Diamond-Blackfan y el síndrome de Shwachman-Diamond.

PALABRAS CLAVE: Anemias raras; anemia ferropénica; talasemia; eritrocitos; hemoglobina; anemia de Fanconi; disqueratosis congénita; anemia de Diamond-Blackfan; síndrome de Shwachman-Diamond.

\section{RARE ANEMIAS AND HEREDITARY BONE MARROW FAILURE}

Copyright: (c) 2018 CSIC. Este es un artículo de acceso abierto distribuido bajo los términos de la licencia de uso y distribución Creative Commons Reconocimiento 4.0 Internacional (CC BY 4.0).

ABSTRACT: Rare anemias and inherited bone marrow failure syndromes are characterized, respectively, by decreased concentrations of hemoglobin or defects in the production of hematopoietic cells leading to single to multiple lineage cytopenias. They are rare and difficult to diagnose due to clinical, cytological and genetic heterogeneity. In this paper, we first address the diagnosis of rare anemias and their causes including marrow failures, erythrocyte defects and disorders of red cell metabolism factors involved in erythrocyte maturation. Finally, we introduce inherited bone marrow failure syndromes and their associated pathologies such as congenital malformations and tumor predisposition, with particular emphasis on the most common diseases: Fanconi anemia, dyskeratosis congenita, Diamond-Blackfan anemia and Shwachman-Diamond syndrome.

KEYWORDS: Rare anemias; ferropenic anemia; thalassemia; erythrocyte; hemoglobin; Fanconi anemia; congenital dyskeratosis; Diamond-Blackfan anemia; Shwachman-Diamond syndrome. 


\section{ANEMIAS RARAS}

\subsection{Introducción a las anemias raras}

La anemia, o disminución de la concentración de hemoglobina $(\mathrm{Hb})$ en la sangre, es la manifestación de un trastorno del organismo que afecta al sistema hematopoyético. Aunque se trata de una condición muy común en la patología humana, sus causas pueden ser muy diversas, y a veces difíciles de identificar. La más frecuente y, por ello, la mejor conocida, es la falta de hierro o anemia ferropénica, presente, en mayor o menor grado, en todos los países del mundo (Pasricha, 2014). Por esta razón, no es infrecuente considerar la anemia como una enfermedad, o como la consecuencia de una alimentación inadecuada. La realidad es muy distinta, ya que en la anemia, al ser un signo, y no una enfermedad, conocer su causa es un requisito imprescindible para iniciar cualquier tipo de tratamiento. En condiciones normales, la concentración de Hb, varía con la edad y el sexo y, por ello, la Organización Mundial de la Salud (OMS) considera que existe anemia cuando la concentración de $\mathrm{Hb}$ es inferior a $110 \mathrm{~g} / \mathrm{L}$ en niños, a $120 \mathrm{~g} / \mathrm{L}$ en mujeres jóvenes no embarazadas y a $130 \mathrm{~g} / \mathrm{L}$ en varones (World Health Organization, 2011). Afortunadamente, la medida de la concentración de hemoglobina es, hoy en día, muy asequible, ya que todos los analizadores hematológicos automatizados la realizan de forma rápida, precisa y económica.

En este contexto, las anemias raras constituyen un grupo heterogéneo de enfermedades raras que debido a su baja prevalencia (< 5 por cada 10.000 habitantes) son poco conocidas, incluso entre los profesionales de la salud. Debido a ello, los pacientes suelen permanecer largos periodos de tiempo sin diagnosticar, o con un diagnóstico incorrecto, lo que imposibilita conocer el pronóstico de la enfermedad, o realizar un consejo genético para futuros embarazos. Esta situación comporta un estado de ansiedad tanto para los pacientes, como para sus familiares, que viene agravado por la ausencia de tratamiento, en general, paliativo, y limitado a transfusiones de sangre, a la administración de quelantes de hierro y estimuladores de la eritropoyesis, o a la extirpación del bazo (esplenectomía). El único tratamiento curativo, el trasplante de progenitores hematopoyéticos, no siempre es aconsejable dada la elevada morbilidad asociada a la intervención y la frecuente ausencia de donantes emparentados. Es por todo ello por lo que las anemias raras, mayoritariamente hereditarias, constituyen hoy en día un importante problema clínico y sociosanitario.
Al objeto de disminuir las desigualdades en la atención sanitaria que en Europa padecen este colectivo de pacientes, la Comisión Europea (EC) viene promocionando, desde el año 2002, la creación de redes de expertos europeos en enfermedades raras, una de las cuales es la dedicada a las anemias raras o ENERCA (European Network for Rare and Congenital Anaemias). Actualmente, en ENERCA se incluyen 63 anemias raras, desde las ultra raras, como, por ejemplo, la anemia de Fanconi o la hemoglobinuria paroxística nocturna (HPN), hasta las menos raras como las hemoglobinopatías, talasemias y anemias hemolíticas (www.enerca.org). El principal objetivo de ENERCA es ayudar a los profesionales de la salud a realizar una mejor atención sanitaria a aquellos pacientes con algún tipo de anemia rara. Después de diez años de funcionamiento, la experiencia de ENERCA ha demostrado que el médico, al acceder fácilmente a una información veraz y contrastada, puede diagnosticar una anemia rara de manera más rápida, y el paciente, al tener un fácil acceso a la web, puede conocer mejor su enfermedad y obtener, si lo desea, una segunda opinión. Esto último ha contribuido decisivamente a disminuir su estado de ansiedad y a mejorar su confianza en el sistema de salud. Actualmente está en desarrollo una plataforma de medicina a distancia (telemedicina) que contribuirá a facilitar, aún más, la accesibilidad a la información, independientemente del lugar de residencia (Vives Corrons, 2013).

\subsection{Abordaje diagnóstico de las anemias raras}

Como en toda anemia, el diagnóstico de una anemia rara tiene su inicio en un minucioso examen clínico del paciente, realizado la mayoría de veces por el médico de familia o el especialista en medicina interna. La intensidad del síndrome anémico depende de su causa, y puede variar desde una anemia bien tolerada o compensada hasta formas muy graves dependientes de hipertransfusión. El inicio neonatal de la enfermedad (anemia e ictericia) es relativamente frecuente, así como la disminución progresiva de la anemia con el crecimiento. Lo habitual es la anemia crónica que, con ciertas variaciones, suele persistir durante toda la vida, por lo que no es infrecuente la aparición de las complicaciones como las úlceras maleolares o la litiasis biliar (Sans-Sabrafen, Besses Raebel y Vives Corrons, 2006). Otras veces la anemia aparece de forma aguda y bajo forma de crisis hemolíticas que suelen ser desencadenadas por agentes diversos como infecciones intercurrentes o la ingesta de ciertas substancias oxidantes. El diagnóstico de una anemia requiere tres exploraciones básicas: 1) hemograma o examen 
hematológico básico, 2) recuento de reticulocitos o hematíes jóvenes circulantes y 3) examen morfológico de la sangre a partir de un frotis.

El hemograma informa del estado de la serie roja suministrando el valor de la concentración de hemoglobina $(\mathrm{Hb})$, clave diagnóstica de la anemia, del número de hematíes circulantes, y de su tamaño (VCM). Algunos analizadores hematológicos automatizados suministran también la concentración promedio de la hemoglobina contenida en los hematíes (CCMH) y la amplitud de la curva de distribución del volumen eritrocitario (RDW). El recuento de reticulocitos indica la capacidad de la médula ósea para contrarrestar la intensidad de la anemia, y junto al VCM constituye hoy en día el criterio más útil para realizar una primera orientación diagnóstica de una anemia (Vives Corrons y Aguilar i Bascompte, 2014). El examen de frotis de sangre es, muchas veces, decisivo para el diagnóstico de una anemia. Como señala Barbara Bain (Bain, 2005) a pesar de los avances en el recuento automatizado de células sanguíneas, el examen del frotis sanguíneo conserva aún todo su valor en el diagnóstico etiológico de las anemias hemolíticas y en el diagnóstico diferencial de la macrocitosis.

Una vez confirmado el diagnóstico de anemia, es fundamental conocer su causa ya que de ello dependen el pronóstico y el tratamiento más adecuado. Para ello se requieren exámenes o pruebas específicas complementarias cuya selección viene facilitada por el empleo de diagramas de flujo (www.eneca.org). Muchas de las pruebas que se mencionan en los diagramas de flujo pueden ser realizadas en laboratorios clínicos convencionales, pero otras se hallan solo al alcance de laboratorios especializados o de eritropatología.

\subsection{Causas de las anemias raras}

Más del $80 \%$ de las anemias raras son hereditarias, y el resto aparecen en el curso de enfermedades no debidas a trastornos del sistema hematopoyético (anemias secundarias). El diagnóstico de una anemia rara exige tener siempre en cuenta esta posibilidad y realizar el correspondiente diagnóstico diferencial. No cabe duda de que esto exige pericia, habilidad clínica y un gran conocimiento de las enfermedades en general, solo al alcance de profesionales con buena formación en medicina interna. Un ejemplo de ello es la enfermedad de Rendu-Osler (telangiectasia hereditaria), donde la anemia suele ser prácticamente siempre el primer síntoma. Durante muchos años, el desconocimiento de esta enfermedad ha conllevado su consideración como causa de anemia rara, cuan- do en realidad se trata de una anemia ferropénica secundaria a las micro hemorragias crónicas. Igualmente pueden ser consideradas anemias raras las que se asocian a enfermedades crónicas raras, como, por ejemplo, las anemias de base inmune, los defectos de absorción y ciertas enfermedades de la sangre como los síndromes mielodisplásicos (SMD). La red europea ENERCA contribuye activamente con ORPHANET y la OMS a la actualización de la clasificación internacional de enfermedades (ICD-10) de la sangre y los órganos hematopoyéticos, donde las anemias se sitúan en tres grandes grupos: 1) D50-D53 (anemias nutricionales), 2) D54-D59 (anemias hemolíticas), y 3) D60-D64 (aplasia medular y otras anemias). En un sentido práctico, las causas de las anemias raras pueden ser de tres tipos: fallos de la médula ósea, defectos del hematíe y trastornos metabólicos de los factores de maduración.

\subsubsection{Anemias raras debidas a fallos de médula ósea}

Los fallos medulares obedecen a defectos congénitos o adquiridos de la hematopoyesis que pueden tener un carácter cuantitativo (aplasia selectiva de serie roja o eritroblastopenia) o cualitativo (trastornos de la maduración o diseritropoyesis). El resultado final es un descenso de la eritropoyesis efectiva y del número de reticulocitos (anemia arregenerativa). Como veremos más en detalle en el apartado segundo de este artículo, la gran mayoría de los fallos medulares tienen un origen congénito y entre ellos destacan la anemia de Fanconi, la eritroblastopenia selectiva o anemia de Diamond-Blackfan y la anemia diseritropoyética congénita (CDA). La CDA es, en realidad, un grupo heterogéneo de defectos de la eritropoyesis con aborto medular de los eritroblastos antes de madurar a reticulocitos (diseritropoyesis) e importante alteración de la morfología eritrocitaria. Clínicamente cursa con anemia, generalmente macrocítica y sobrecarga de hierro. Hasta la actualidad se han descrito cinco formas clínicas de CDA: CDA I, CDA II, CDA III, CDA IV y CDA con trombocitopenia (Iolascon, Heimpel, Wahlin y Tamary, 2013). Las dos primeras (CDA I y CDA II) tienen un patrón hereditario autosómico recesivo y las dos siguientes (CDA III y CDA IV) autosómico dominante. La trombocitopenia con CDA tiene una herencia ligada al cromosoma $X$.

CDA I (OMIM 224120). En muchos casos obedece a mutaciones del gen CDAN1, que codifica para una chaperona o proteína de interacción, o del gen C15ORF41, que codifica para una endonucleasa supuestamente implicada en la replicación del ADN o ensamblaje de la cromatina. En otros casos la mutación causante de la enfermedad se desconoce. Se ca- 
racteriza por una marcada diseritropoyesis en la que destacan los puentes cromatínicos internucleares.

CDA II (OMIM 224100). Obedece a mutaciones en el gen SEC23B, que codifica una proteína implicada en la función del aparato de Golgi. Se caracteriza por una marcada diseritropoyesis en la que destaca la presencia de binuclearidad o multinuclearidad eritroblástica con presencia de una doble membrana celular en un elevado porcentaje de eritroblastos.

CDA III (OMIM 105600). Obedece a mutaciones en el gen KIF23, que codifica una proteína (MKLP1) necesaria para la movilidad celular. Se caracteriza por una marcada diseritropoyesis en la que destaca la presencia de marcadas alteraciones de la cromatina nuclear y el tamaño de los eritroblastos dando una imagen prácticamente superponible a la eritroleucemia o enfermedad de Di-Guglielmo.

CDA IV (OMIM 613673). Obedece a mutaciones en los genes que codifican factores de transcripción eritroide y GATA1. Es tan poco frecuente que sus características morfológicas están aún por definir con precisión.

CDA con trombocitopenia (OMIM 300367). Es un trastorno ligado al sexo (cromosoma $\mathrm{X}$ ) que se hereda con carácter autosómico recesivo y caracterizado por trombocitopenia y alteraciones morfológicas de las plaquetas que en algunos pacientes se acompaña de diseritropoyesis intensa.

\subsubsection{Anemias raras debidas a defectos del hematie}

Los defectos de los hematíes pueden ser a) intrínsecos o de causa hereditaria y debidos a alteraciones estructurales o funcionales de sus componentes fundamentales: la hemoglobina (hemoglobinopatías), la membrana (membranopatías) o las enzimas del metabolismo (enzimopatías), y b) extrínsecos o de causa adquirida y producidos por alteraciones del plasma sanguíneo o del sistema vascular. En cualquier caso, el resultado final es siempre un síndrome hemolítico de intensidad variable con aumento compensador de la eritropoyesis y aumento del número de reticulocitos. Clínicamente se caracterizan por tres signos que cuando van unidos son de gran utilidad diagnóstica: 1) reticulocitosis, 2) esplenomegalia y 3 ) ictericia.

\subsubsection{Defectos hereditarios del hematie}

Dentro de este grupo de anemias hereditarias se incluyen las hemoglobinopatías (estructurales y talasemias), más frecuentes en el sur de Europa, y las eritroenzimopatías y membranopatías, de prevalencia muy inferior a las anteriores y consideradas como anemias ultra raras.
HEMOGLOBINOPATÍAS. Obedecen a mutaciones en los genes de globina, que pueden alterar la síntesis (talasemias) o la estructura de la hemoglobina (hemoglobinopatías estructurales). Su prevalencia mundial se estima en alrededor de 269 millones de portadores, pero en Europa existen poblaciones de riesgo, en especial para las talasemias, que se localizan en las regiones que rodean el mar Mediterráneo (anemia mediterránea) y cuya prevalencia es de uno a cinco casos por cada 2.000 habitantes. Es de señalar que, a lo largo de los últimos 30 años, en muchos países de la Unión Europea (UE), se ha observado un aumento de la prevalencia de hemoglobinopatías no autóctonas debido al impacto inmigratorio de poblaciones procedentes de otras áreas geográficas donde estas enfermedades son prevalentes (África, Asia y centro América).

Entre ellas destaca la hemoglobinopatía $S$ (HbS; OMIM 603903), prevalente en las poblaciones del África subsahariana o central debido a la protección que ofrece contra la malaria o paludismo. La $\mathrm{HbS}$ obedece sustitución de valina por ácido glutámico en la sexta posición de la cadena beta de la globina y en su forma homocigota o combinada con otras hemoglobinopatías es responsable de la llamada enfermedad de células falciformes (ECF) o drepanocitosis. La ECF evoluciona bajo forma de crisis de hemólisis (anemia) y vaso-oclusivas con micro infartos (dolor) desencadenadas por la hipoxia que, al disminuir la solubilidad de la $\mathrm{HbS}$, la precipita, distorsionando la forma del hematíe (hematíes falciformes) y disminuyendo drásticamente su capacidad de deformación. Estas crisis cursan con anemia regenerativa ( $\mathrm{Hb}: 70 \mathrm{a}$ $110 \mathrm{~g} / \mathrm{L})$, dolor abdominal y crisis vaso-oclusivas muy dolorosas que afectan muchos tejidos del organismo, especialmente articulaciones y sistema músculo-esquelético. El frotis de sangre muestra hematíes falciformes (véase figura 1).

El diagnóstico de la ECF requiere un estudio de hemoglobinas (Vives Corrons y Aguilar i Bascompte, 2014; Bain, 2011) y la demostración de la mutación mediante biología molecular. Durante la primera infancia son frecuentes complicaciones sobreañadidas como, por ejemplo, el retraso del crecimiento y puberal, hipoesplenismo secundario con infartos esplénicos repetidos y susceptibilidad a infecciones graves tales como infecciones pulmonares recurrentes con infartos repetidos, abscesos óseos y del tracto genitourinario y la sepsis neumocócica, muchas veces causa de la muerte del paciente. Otras complicaciones frecuentes son la hipertrofia cardiaca secundaria a la anemia; necrosis papilar renal con hematuria, pérdi- 
Figura 1. Hematíes falciformes (alargados) en un paciente con drepanocitosis

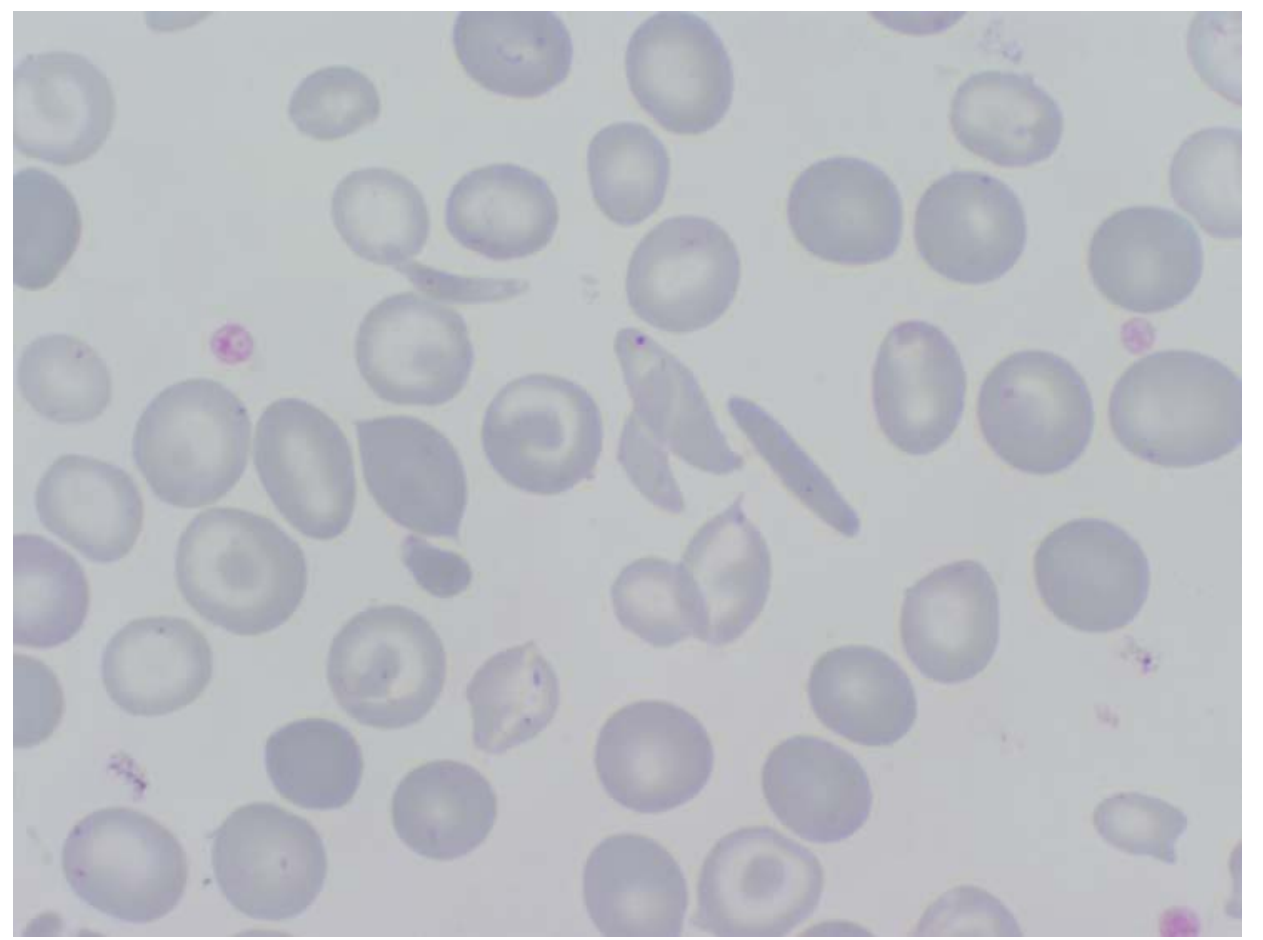

da de la capacidad de concentración renal, priapismo; cálculos biliares, cirrosis hepática; necrosis avascular del fémur y el húmero; accidentes cerebrovasculares (ACV); convulsiones y alteraciones visuales. En pacientes sometidos a hipertransfusión, a todo ello deben añadirse las complicaciones debidas a la sobrecarga de hierro. Actualmente gracias a la posibilidad de realizar un diagnóstico precoz de la enfermedad mediante cribado neonatal de la ECF, puede instaurarse un tratamiento preventivo desde los primeros años de vida, con lo que la frecuencia de las complicaciones se reduce significativamente y la mortalidad durante la primera infancia disminuye drásticamente. No existe un tratamiento específico para la ECF, aunque sí preventivo a base de realizar una vida saludable junto a la administración de vacuna antineumocócica polivalente y ácido fólico. En casos de crisis vaso-oclusivas, la hidratación, la administración de analgésicos y el tratamiento de las causas desencadenantes son la única terapéutica eficaz contra el dolor. En casos graves se recomienda también la administración de hidroxiurea (HU) ya que al aumentar la concentración de HbF, disminuye la frecuencia de las crisis vaso-oclusivas, la necesidad de transfusiones, y sobre todo la aparición del síndrome torácico agudo. En los niños la hipertransfusión suele mejorar el pronóstico.
Además de la HbS existen otras hemoglobinopatías estructurales de interés clínico como la $\mathrm{HbS}, \mathrm{HbJ}$ $\mathrm{HbD}$ y las hemoglobinas inestables, llamadas también hemoglobinopatías congénitas con cuerpos de Heinz que obedecen a sustituciones de aminoácidos cerca del grupo hemo que afectan la estabilidad de la molécula de hemoglobina. En presencia de un agente oxidante, las hemoglobinas inestables precipitan y se forman cuerpos de inclusión eritrocitarios o cuerpos de Heinz. Clínicamente cursan con un síndrome hemolítico crónico de intensidad variable. El diagnóstico requiere una tinción para cuerpos de Heinz y un estudio de hemoglobinas (Vives Corrons y Aguilar i Bascompte, 2014). Este grupo, a diferencia que la ECF, presenta un patrón de herencia autosómico dominante.

TALASEMIAS. Obedecen a la disminución de la síntesis de alguna de las cadenas de globina (alfa o beta), debido a ausencia, disminución o traducción defectuosa de ARN mensajero específico (ARNm) causada por deleciones o mutaciones puntiformes de los genes de globina implicados. Mientras que las mutaciones puntiformes predominan en los genes beta, las grandes deleciones son más frecuentes en los genes alfa. De acuerdo con el tipo de mutación y la intensidad de la disminución de síntesis, la gravedad del cuadro 
clínico puede ser más o menos intensa. En la beta talasemia las formas más leves consisten en una discreta o moderada anemia hipocroma y microcítica (rasgo talasémico) mientras que las más graves, con anemia intensa, pueden clasificarse en "talasemia mayor" o "talasemia intermedia" según tengan o no requerimiento transfusional periódico, respectivamente. En la alfa talasemia, como el clúster genético tiene dos genes, la mutación de un único alelo, relativamente frecuente en nuestra población, carece de anemia y cursa solo con discreta microcitosis, mientras que la de dos alelos cursa como un rasgo talasémico (anemia microcítica leve o moderada). La mutación de tres alelos da lugar a la llamada hemoglobinopatia $\mathrm{H}$, una forma clínica superponible a la beta talasemia intermedia pero con presencia de $\mathrm{HbH}$ o tetrámeros betaglobina, resultado del exceso de estas cadenas por la disminución de cadenas alfa. La pérdida completa de los cuatro alelos (alfa-talasemia homocigota) es incompatible con la vida (hidropesía fetal).

El diagnóstico de ambas formas de talasemia se basa en los datos aportados por el hemograma y por el estudio de hemoglobinas mediante electroforesis o cromatografía líquida de alta resolución (HPLC). En el caso de la beta talasemia, se observa siempre un aumento de la fracción $\mathrm{HbA2}$, y en las formas más graves también de $\mathrm{HbF}$, mientras que en la alfa talasemia el patrón de hemoglobinas es normal, siendo necesario recurrir a la biología molecular. Un estudio familiar preciso es también muy importante para prevenir errores diagnósticos y la aplicación de tratamientos innecesarios. Además, la correcta identificación de los estados portadores para cualquier tipo de hemoglobinopatía permitirá identificar parejas de riesgo, es decir, donde ambos miembros de la pareja son portadores asintomáticos de alguna hemoglobinopatía; en estas parejas, como en cualquier enfermedad con patrón de herencia autosómico recesivo, el porcentaje de tener un descendiente afectado de un trastorno grave de la hemoglobina es del $25 \%$ en cada embarazo.

MEMBRANOPATIAS. Obedecen a defectos estructurales o funcionales de las proteínas de la membrana eritrocitaria. En general se heredan con carácter autosómico dominante pero existen formas que se transmiten con carácter recesivo. La esferocitosis hereditaria (EH; OMIM 182870, 182900, 270970, 612653, 612690) es la causa más frecuente de anemia hemolítica congénita en la raza blanca y obedece a un defecto de proteínas del esqueleto de la membrana que producen vesiculación y pérdida parcial de la misma con la consi- guiente disminución de la relación superficie/volumen y aparición de esferocitos (véase figura 2).

Las proteínas mayormente afectadas en la EH son la espectrina y la Banda 3. La hemólisis se produce casi exclusivamente en el bazo, con lo que la anemia hemolítica suele asociarse a intensa esplenomegalia, palpable en el $75 \%$ al $80 \%$ de los casos. Junto a ello, son especialmente frecuentes las complicaciones del síndrome hemolítico crónico como, por ejemplo, la ictericia intermitente con aumento de pigmentos y formación prematura de cálculos biliares, la crisis de eritroblastopenia transitoria por infección del parvovirus B19 o déficit de folato o la formación de úlceras maleolares tórpidas (King y Zanella, 2013). El diagnóstico de la EH se basa en la triada: 1) anemia con ictericia, 2) intensa esplenomegalia y presencia de esferocitos circulantes (esferocitosis), fácilmente demostrables mediante el examen morfológico de la sangre. Una prueba que sirve para demostrar de forma indirecta la esferocitosis es la resistencia osmótica eritrocitaria (ROE) que muestra un aumento de la hemólisis cuando los glóbulos rojos se colocan en una solución salina hipotónica. La hemólisis se incrementa en gran medida si los hematíes se incuban primero sin glucosa a la temperatura corporal durante 24 horas (véase figura 3).

La implementación de los analizadores hematológicos automatizados que determinan la $\mathrm{CCMH}$ mediante un sistema directo permite utilizar esta magnitud como criterio de $\mathrm{EH}$ cuando se halla aumentada en presencia de un recuento elevado de reticulocitos. Finalmente la utilización de la técnica del EMA-binding test se está implementando actualmente como técnica de referencia, especialmente en el diagnóstico de la EH. La técnica del EMA-binding test se basa en la medida de la intensidad de fluorescencia en hematíes que han sido incubados con un fluorocromo, la eosin-5-maleimida (EMA). El EMA se une de manera específica al transportador de aniones (Banda 3). El dominio citoplasmático $\mathrm{N}$-terminal de la Banda 3 interactúa con otras proteínas como la anquirina y la proteína 4.2, que a su vez están unidas al citoesqueleto de espectrina que estabiliza la membrana lipídica. La sensibilidad y especificidad del EMA-binding test han sido evaluadas para la detección de anemias hemolíticas debidas a defectos de membrana en distintos estudios. Esta técnica es especialmente sensible en la detección de $\mathrm{EH}$, por lo que actualmente se incluye en el algoritmo diagnóstico de esta enfermedad (Kedar, Colah, Kulkarni, Ghosh y Mohanty, 2003; Bianchi, Fermo y Zanella, 2012). De la misma manera, el EMAbinding test también se emplea en el diagnóstico de 
Figura 2. Esferocitos (más pequeños y densos) en un paciente con esferocitosis hereditaria

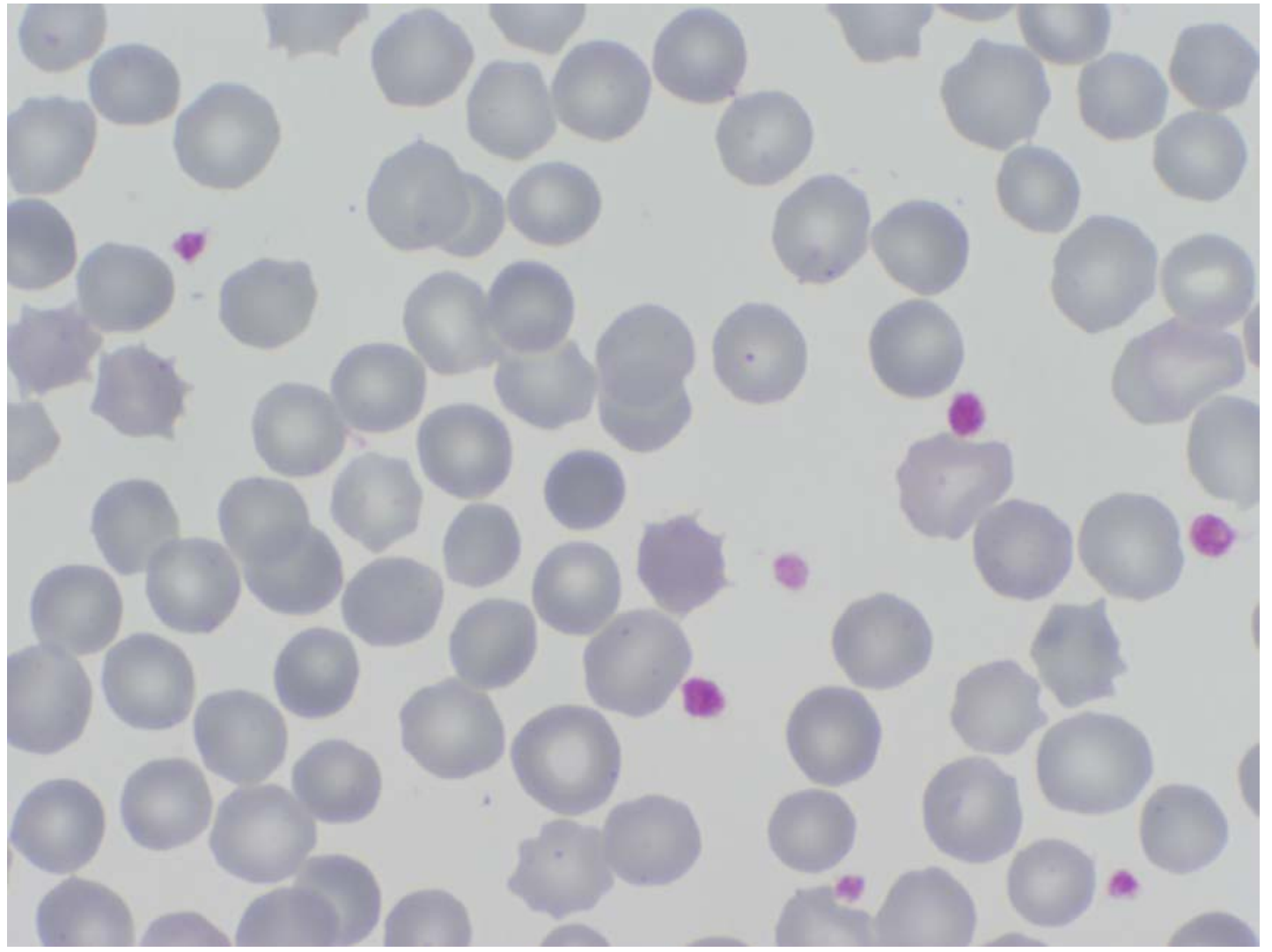

Figura 3. Curva de fragilidad osmótica eritrocitaria

$$
\begin{aligned}
& \text { a463 }
\end{aligned}
$$

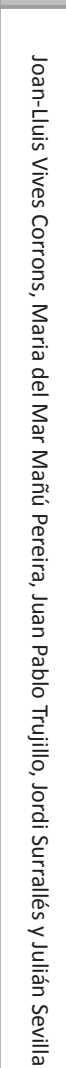

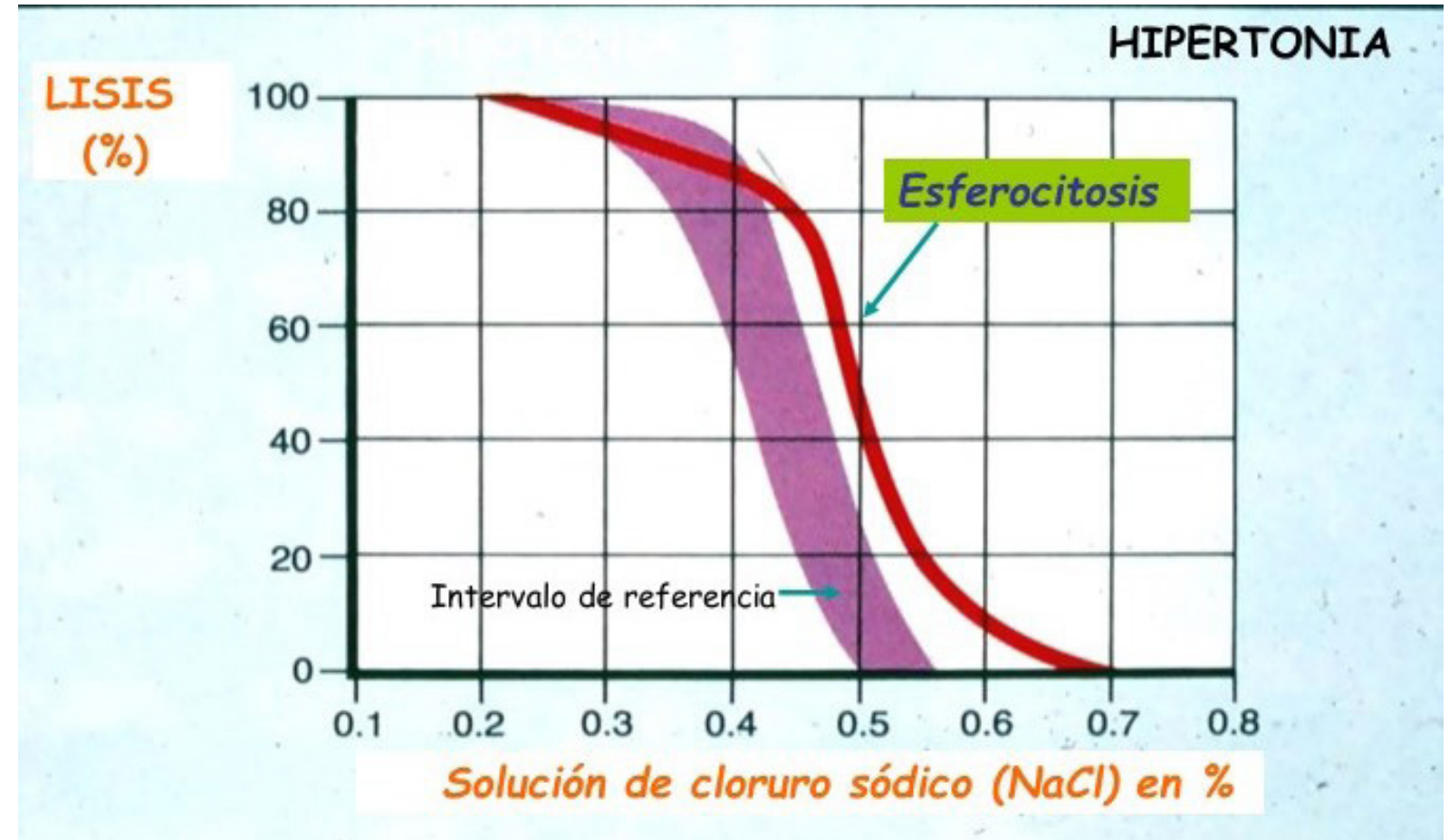


otras membranopatías como la eliptocitosis hereditaria (HE). El tratamiento de la $\mathrm{EH}$ es exclusivamente preventivo a base de la administración de ácido fólico y cuando la anemia es muy intensa puede ensayarse la extirpación del bazo (esplenectomía) ya que, en la mayoría de los casos, normaliza la concentración de hemoglobina y desaparece la anemia (aunque no los esferocitos circulantes). Debido al importante efecto defensivo del bazo frente a infecciones, en algunos casos la esplenectomía se ha asociado a sepsis neumocócica fulminante (especialmente en niños menores de cinco años) por lo que en todos los casos, antes de la esplenectomía, debe administrarse vacuna antineumocócica polivalente.

Otra membranopatía hereditaria es la eliptocitosis congénita (EC; OMIM 109270, 130600, 179650, 225450,611804), trastorno algo más leve clínicamente que la EH. En la EC es característica la presencia de numerosos eliptocitos circulantes en sangre periférica (véase la figura 4).

Al igual que la EH, la EC obedece a un defecto de proteínas del esqueleto (principalmente Banda 4,1) que alteran la elasticidad de la membrana impidiendo su recuperación después de un alargamiento. No existe pérdida de membrana y, por ello, la ROE y la $\mathrm{CCMH}$ son normales. En casos graves, como, por ejemplo, la piropoiquilocitosis hereditaria (PPH), la esplenectomía puede ser también beneficiosa, pero nunca tanto como lo es la EH.

Finalmente existe una forma muy rara de membranopatía cuya manifestación morfológica fundamental es la estomatocitosis hereditaria (OMIM 194380, 185000), es decir, la presencia de hematíes con una palidez central alargada en lugar de redonda (véase figura 5).

Su mecanismo genético y molecular es poco conocido, aunque sí se sabe que en todas las formas existe un trastorno de la permeabilidad a los iones sodio o potasio por el cual el hematíe puede hidratarse (xerocitosis congénita) o deshidratarse (hidrocitosis congénita). Todas estas formas cursan con un síndrome hemolítico con marcada reticulocitosis pero escasa anemia. La esplenectomía está recomendada porque facilita la aparición de trombosis (trombofilia).

ERITROENZIMOPATIAS. Son enfermedades hereditarias que alteran el metabolismo del eritrocito dando lugar a tres fenotipos diferentes: a) síndrome hemolítico (agudo o crónico) con anemia, b) cianosis con metahemoglobinemia o c) eritrocitosis o poliglobulia. La

Figura 4. Eliptocitos (hematíes elípticos y ovalados) en un paciente con eliptocitosis hereditaria

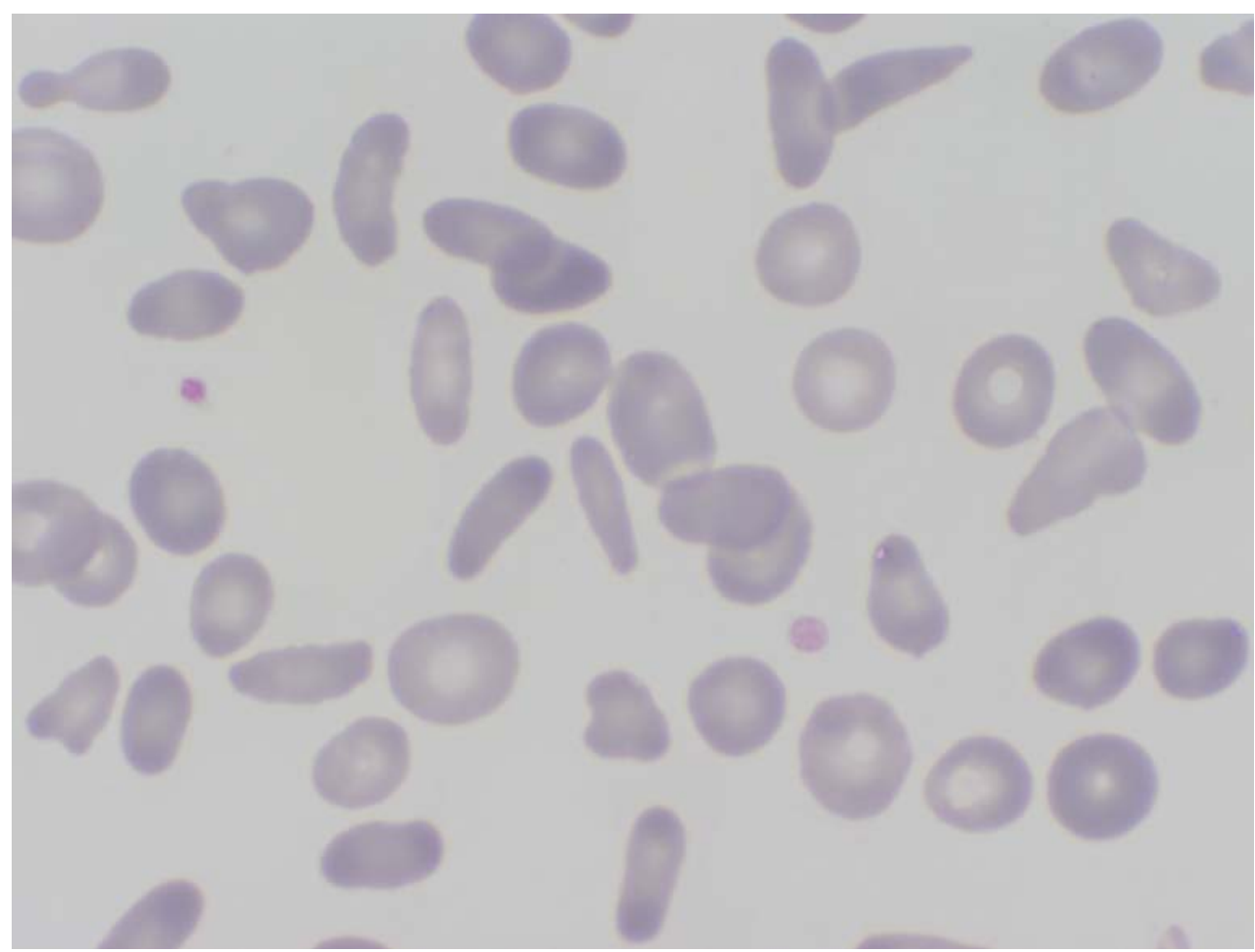


Figura 5. Estomatocitos. Hematies en los que la palidez central (siempre redonda) tiene forma alargada o de boca

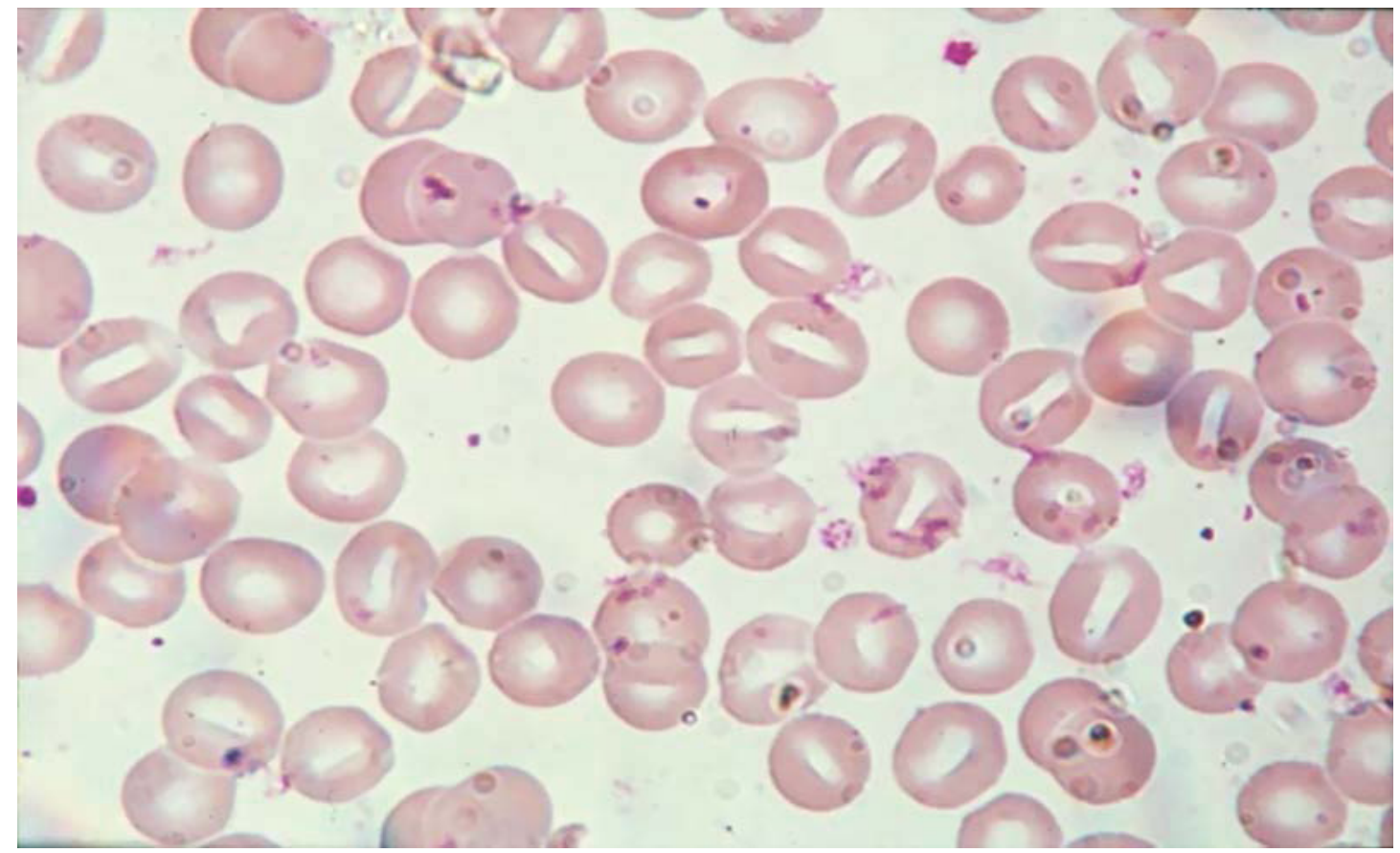

asociación entre la alteración enzimática y la anemia hemolítica se ha descrito en 14 de los 38 enzimas que conforman el metabolismo eritrocitario (véase tabla 1).

Algunos déficits enzimáticos producen hemolisis solo bajo estrés celular producido por infecciones, medicamentos oxidantes o por la ingesta de habas. Otros déficits enzimáticos están asociados a anemia hemolítica crónica no esferocítica (AHCNE). En algunas ocasiones, la expresión del déficit no está restringida al eritrocito sino que se extiende a otros tejidos, principalmente al neurológico, hepático o muscular con aparición de neuropatía, hepatopatía o miopatía asociadas a la anemia. El hematíe es especialmente vulnerable a las enzimopatías porque a diferencia de otras células no puede resintetizar las enzimas deficientes ya que carece de núcleo y ribosomas. Las deficiencias enzimáticas se producen cuando alguna de las enzimas de su reducido metabolismo es inestable y desaparece muy rápidamente, o ha perdido funcionalidad catalítica y carece de actividad. En el hematíe maduro existen dos vías metabólicas fundamentales: 1) la glucolisis anaerobia por la que la glucosa se utiliza para generar ATP y 2) el sistema antioxidante por el que elimina cualquier agresión oxidativa para generar NADH y NADPH. EI ATP se utiliza para cumplir con los requisitos energéticos y el NADH para reducir la metahemoglobina. EI NADPH se utiliza para reducir el glutatión oxidado que a su vez se requiere para mantener los grupos sulfhidrilo de proteínas en un estado reducido y para desintoxicar peróxido de hidrógeno (véase figura 6).

Se han descrito enzimopatías en ambas rutas metabólicas. El déficit de glucosa-6-fosfato deshidrogenasa (G6PD; OMIM 300908, 134700) es la más frecuente del sistema antioxidante, y muestra transmisión hereditaria ligada al sexo. Es especialmente frecuente en África, Asia y en la región mediterránea (Grecia e Italia, principalmente) y, debido a su carácter polimórfico, tiene muchas variantes entre las que destacan las G6PD A-, predominantes en la raza negra, y las G6PD Mediterráneas, predominantes en la raza blanca. En las formas G6PD A-, la enzima es inestable pero la actividad enzimática es casi normal en los reticulocitos, mientras que en las variantes G6PD Mediterráneas, la enzima es aún más inestable y su actividad es muy baja incluso en los reticulocitos. Esto explica que en portadores de G6PD A- el episodio hemolítico agudo sea auto limitado y la recuperación de la anemia sea más rápida que en los portadores de variantes G6PD Mediterráneas. Clínicamente el déficit de G6PD cursa con anemia hemolítica inducida por la ingesta de habas (fabismo) o de ciertos medicamentos oxidantes (anemia hemolítica medicamentosa). Debido a ello, los portadores de un déficit de G6PD pueden per- 
Tabla 1. Enzimopatías asociadas a anemia hemolítica

\begin{tabular}{|c|c|c|c|}
\hline Enzima & Hemólisis & Extra hematológica & Herencia \\
\hline Adenilatocinasa, déficit de & Crónica & Sí neuropatía) & AR \\
\hline Adenosinadeaminasa (ADA), hiperactividad & Crónica & No & $A D$ \\
\hline Aldolasa, déficit de & Crónica & Sí & AR \\
\hline Fosfofructocinasa (PFK) déficit & Crónica & Sí (miopatía, glucogenosis) & AR \\
\hline Fosfogliceratocinasa (PGK), déficit de & Crónica & $\begin{array}{c}\text { Sí (neuropatía, retraso } \\
\text { mental) }\end{array}$ & $\mathrm{XL}$ \\
\hline Glucosa fosfato isomerasa (GPI), déficit de & Crónica & Sí (neuropatía) & AR \\
\hline Glucosa-6-fosfato deshidrogenasa (G6PD), déficit de & $\begin{array}{l}\text { Aguda (frecuente) } \\
\text { Crónica (rara) }\end{array}$ & No & $X L$ \\
\hline 6-fosfogluconato deshidrogenasa & Crónica & Cataratas & AR \\
\hline Gamma glutamil cisteina sintetasa (GGCS), déficit de & Crónica & $\begin{array}{c}\text { Si (neuropatía, acidosis } \\
\text { metabólica) }\end{array}$ & AR \\
\hline Glutation reductasa (GSR), déficit de & Aguda/crónica & Si (cataratas) & AR \\
\hline Glutation sintetasa (GSH-S), déficit de & Crónica & $\begin{array}{c}\text { Si (neuropatía, acidosis } \\
\text { metabólica) }\end{array}$ & $A R$ \\
\hline Hexocinasa (HK), déficit de & Crónica & No & AR \\
\hline Pirimidina 5'-nucleotidasa (P5N), déficit de & Crónica & No & $A R$ \\
\hline Piruvato quinasa (PK), déficit de & Crónica & No & AR \\
\hline Triosa fosfato isomerasa (TPI), déficit de & Crónica & Sí (neuropatía grave & AR \\
\hline
\end{tabular}

Fuente: elaboración propia.

manecer asintomáticos durante muchos años, hasta que se produce este contacto con las substancias que desencadenan la hemólisis. Entre los medicamentos que pueden ser causa de hemólisis en el déficit la deficiencia de G6PD destacan ciertos analgésicos, sulfamidas, antipalúdicos, y antibióticos (Luzzatto y Seneca, 2014). El fabismo, una anemia hemolítica muy intensa inducida por la exposición a las habas o al polen de la planta solo se produce en personas con la variante mediterránea. No todas las familias se ven afectadas, lo que sugiere la necesidad de cierta predisposición genética. También existen formas ultra raras de déficit de G6PD que obedecen a variantes no polimórficas sino esporádicas que cursan con un síndrome hemolítico crónico. Otros factores que pueden inducir hemólisis en el déficit de G6PD son las infecciones virales, especialmente gripe y hepatitis, la cetoacidosis diabética y otras situaciones de estrés diversas.

El diagnóstico del déficit de G6PD se basa en la historia clínica (antecedentes citados) y la exclusión del mecanismo autoinmune mediante la negatividad de la prueba de Coombs. Durante la crisis hemolítica la observación del frotis muestra la presencia de excen- trocitos o hematíes sometidos a un estrés oxidativo (véase figura 7).

Para técnicas de cribado se utiliza la prueba de la mancha fluorescente a base de demostrar la formación de NADPH (fluorescente) a partir de NADP (no fluorescente) o la reducción de la metahemoglobina en presencia de azul de metileno.

El déficit de piruvato quinasa (PK; OMIM 266200) es la enzimopatía más frecuente de la glicolisis anaerobia (vía de Embden-Meyerhof) y es la causa más frecuente de síndrome hemolítico crónico hereditario después de la esferocitosis hereditaria (Zanella, Fermo, Bianchi y Valentini, 2005). Es una enzimopatía mucho menos frecuente que el déficit de G6PD. El diagnóstico de la PK requiere la cuantificación de la actividad enzimática en el hemolizado del paciente. Dado que la anemia hemolítica en el déficit de PK obedece siempre a mutaciones del gen PKLR, los leucocitos tienen una actividad PK normal, por lo que si no se eliminan bien al preparar el hemolizado pueden falsear el resultado y enmascarar la existencia de un déficit de PK eritrocitaria. Para evitar esta importante 
Figura 6. Sistema óxido-reductor del hematíe de substancias oxidantes (habas y ciertos medicamentos)

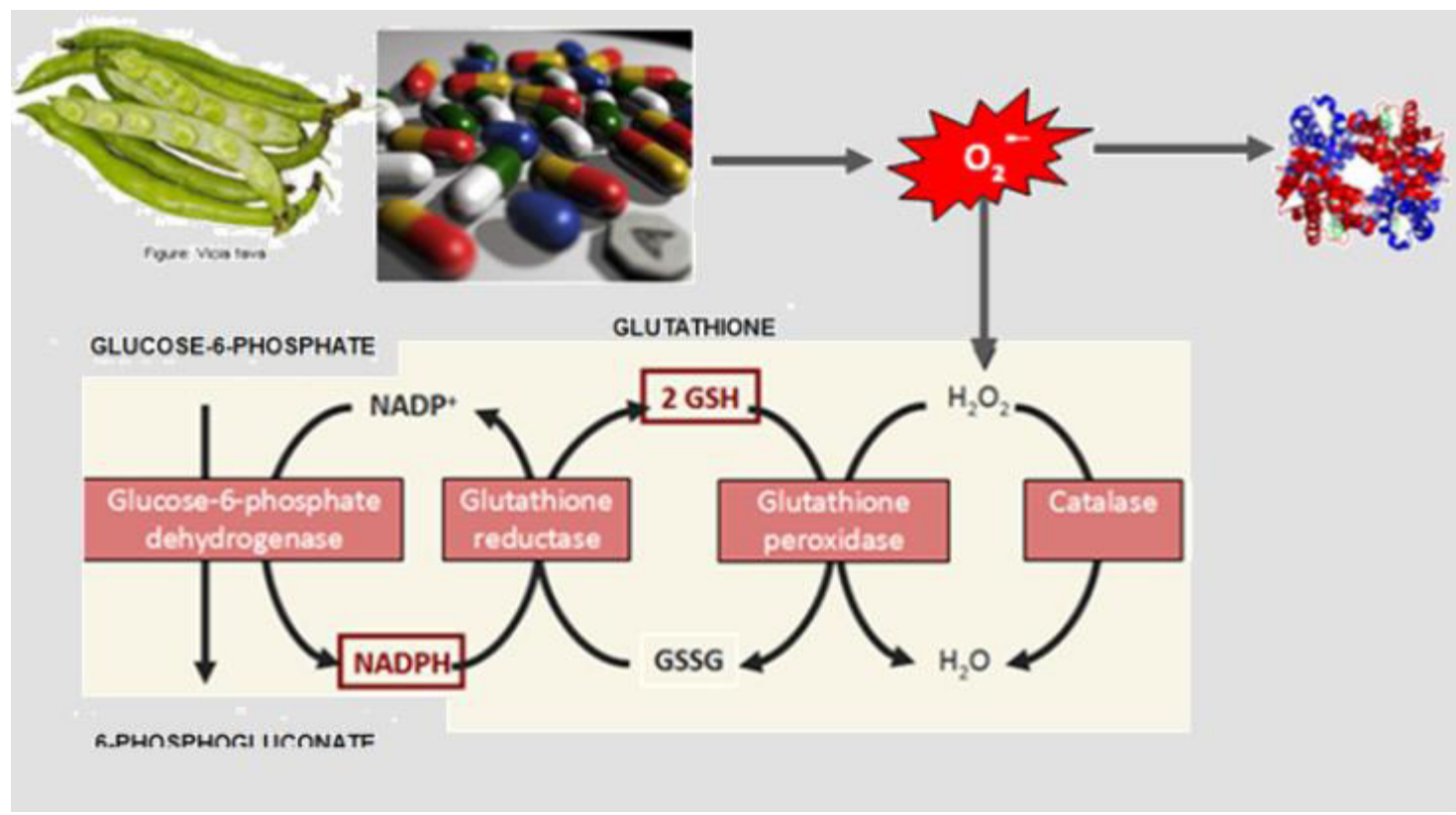

Figura 7. Excentrocitos (hematíes semivacíos) en una paciente con crisis de favismo

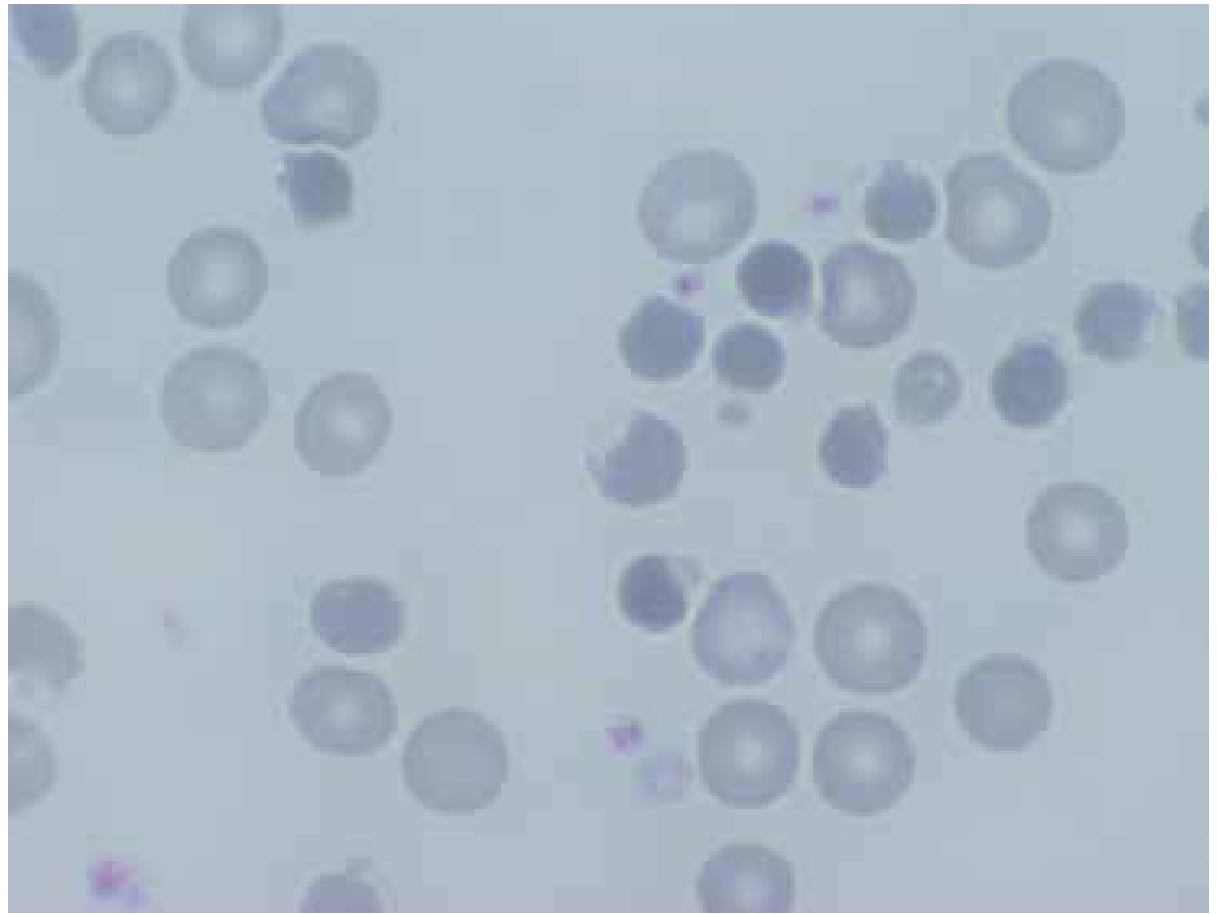

causa de error (falsos negativos), la sangre tratada con anticoagulante debe filtrarse mediante una columna de microcelulosa al objeto de eliminar los leucocitos y plaquetas. Igualmente la presencia de un elevado número de reticulocitos circulantes, muy frecuente en el déficit de PK, puede dar también falsos negativos debido a que la actividad PK de los reticulocitos es muy superior a la de los hematíes maduros. Por ello, si en presencia de intensa reticulocitosis se obtiene una actividad PK normal, debe confirmarse el resul- 
tado mediante la determinación del cociente entre la actividad PK y hexocinasa (HK). La HK es una enzima cuya actividad también aumenta en presencia de reticulocitosis y, por tanto, si este incremento es muy superior al de la PK, el déficit de esta enzima se pone de manifiesto por una disminución significativa del cociente PK/HK.

\subsubsection{Defectos adquiridos del hematie}

Los defectos adquiridos de los hematíes resultan de agresiones extrínsecas a eritrocitos normales por parte de un entorno hostil (alteraciones del plasma o del sistema vascular) como, por ejemplo, la anemia hemolítica autoinmune (AHAI) y la anemia hemolítica mecánica y microangiopática (MAT) o por una mutación somática de la célula madre pluripotente como, por ejemplo, la hemoglobinuria paroxística nocturna (HPN).

ANEMIA HEMOLITICA AUTOINMUNE (AHAI). Aparece cuando existen anticuerpos dirigidos contra un componente de la membrana eritrocitaria o cuando ciertos fármacos que interaccionan con la membrana del hematíe facilitan su fagocitosis por los macrófagos del bazo, del hígado y de la médula ósea. El patrón en cada caso es característico y se determina por la naturaleza y cantidad de auto anticuerpos producidos. En todos los casos el diagnóstico se basa en la demostración de la antiglobulina mediante positividad de la prueba de Coombs directa para IgG o IgM y complemento. En ocasiones el frotis de sangre puede mostrar intensa policromasia debida a la reticulocitosis y esferocitosis (Vives Corrons y Aguilar i Bascompte, 2014; Dacie, 2001).

ANEMIA HEMOLITICA MECANICA Y MICROANGIOPATICA (MAT). Obedece a rotura de los hematíes al pasar por vasos sanguíneos de pequeño calibre y parcialmente trombosados, tal como sucede en la microangiopatía trombótica (MAT), o por grandes vasos con anomalías estructurales derivadas de implantación de prótesis valvulares cardíacas o arteriales con coartación grave de la arteria aorta. La MAT mejor conocida es la púrpura trombótica trombocitopénica (PTT) o síndrome hemolítico urémico (SHU), que es una entidad clínica definida por la tríada: anemia hemolítica no inmune, trombocitopenia grave e insuficiencia renal aguda. El Síndrome hemolítico urémico atípico (SHUa) es una forma de SHU donde la MAT obedece a la pérdida de regulación de la vía alternativa del complemento sobre las superficies celulares de origen genético. El SHUa es una causa de anemia ultra rara que, pese al tratamiento estándar con terapia plasmática, frecuentemente evoluciona hacia la insuficiencia renal crónica terminal, de elevada mor- talidad. En los últimos años, se ha establecido el papel clave que desempeña el sistema del complemento en la inducción de daño endotelial en los pacientes con SHUa, mediante la caracterización de múltiples mutaciones y polimorfismos en los genes que codifican determinados factores del complemento (Noris y Remuzzi, 2009). Para el diagnóstico de la anemia hemolítica mecánica es fundamental la observación del frotis de sangre, ya que suministra la clave diagnóstica por la presencia de hematíes fragmentados o esquistocitos (véase figura 8).

HEMOGLOBINURIA PAROXÍSTICA NOCTURNA (HPN). Es una enfermedad clonal causada por una mutación somática en el gen PIG-A que codifica una proteína involucrada en la síntesis del grupo glicosilfosfatidilinositol (GPI). La mutación ocurre en la céIula madre hematopoyética pluripotente, y por ello el déficit (total o parcia) de GPI afecta la totalidad de las células sanguíneas. El grupo GPI es el puente de unión entre ciertas proteínas funcionales y la membrana celular por lo que, cuando falta, estas no pueden realizar su función. Entre ellas destacan la CD55 y CD59 que intervienen en la protección del hematíe frente a la acción lítica del complemento. Ello explica la hemólisis intravascular mediada por el complemento, la trombosis venosa y la insuficiencia de la eritropoyesis, aunque el mecanismo de la expansión clonal de la población HPN aún se desconoce. El diagnóstico se basa en la demostración, mediante citometría de flujo, del déficit de proteínas GPI (CD55 y CD56) en hematíes y granulocitos. No se utiliza el análisis molecular ya que las mutaciones responsables de la enfermedad no son ni homogéneas ni repetitivas. El diagnóstico diferencial incluye todas las otras formas de anemia (en particular la anemia hemolítica autoinmune), la trombosis de la arteria mesentérica, la obstrucción de la vena porta y una trombosis de la vena renal. Hasta el año 2007, el tratamiento de la HPN era exclusivamente sintomático (transfusiones de sangre y administración de eritropoyetina, glucocorticoides y anticoagulantes), pero a partir de este año la introducción del anticuerpo monoclonal Eculizumab recibió la designación europea de medicamento huérfano para el tratamiento de la HPN (Parker, 2012). El Eculizumab disminuye drásticamente la hemólisis, y con ello la necesidad de transfusiones, pero a la vez reduce las complicaciones trombóticas y el riesgo de insuficiencia renal. El pronóstico de la HPN depende de la frecuencia e intensidad de las crisis hemolíticas, de la trombosis y de la posible aparición de aplasia de médula ósea. 
Figura 8. Hematíes fragmentados en un paciente con síndrome hemolítico urémico

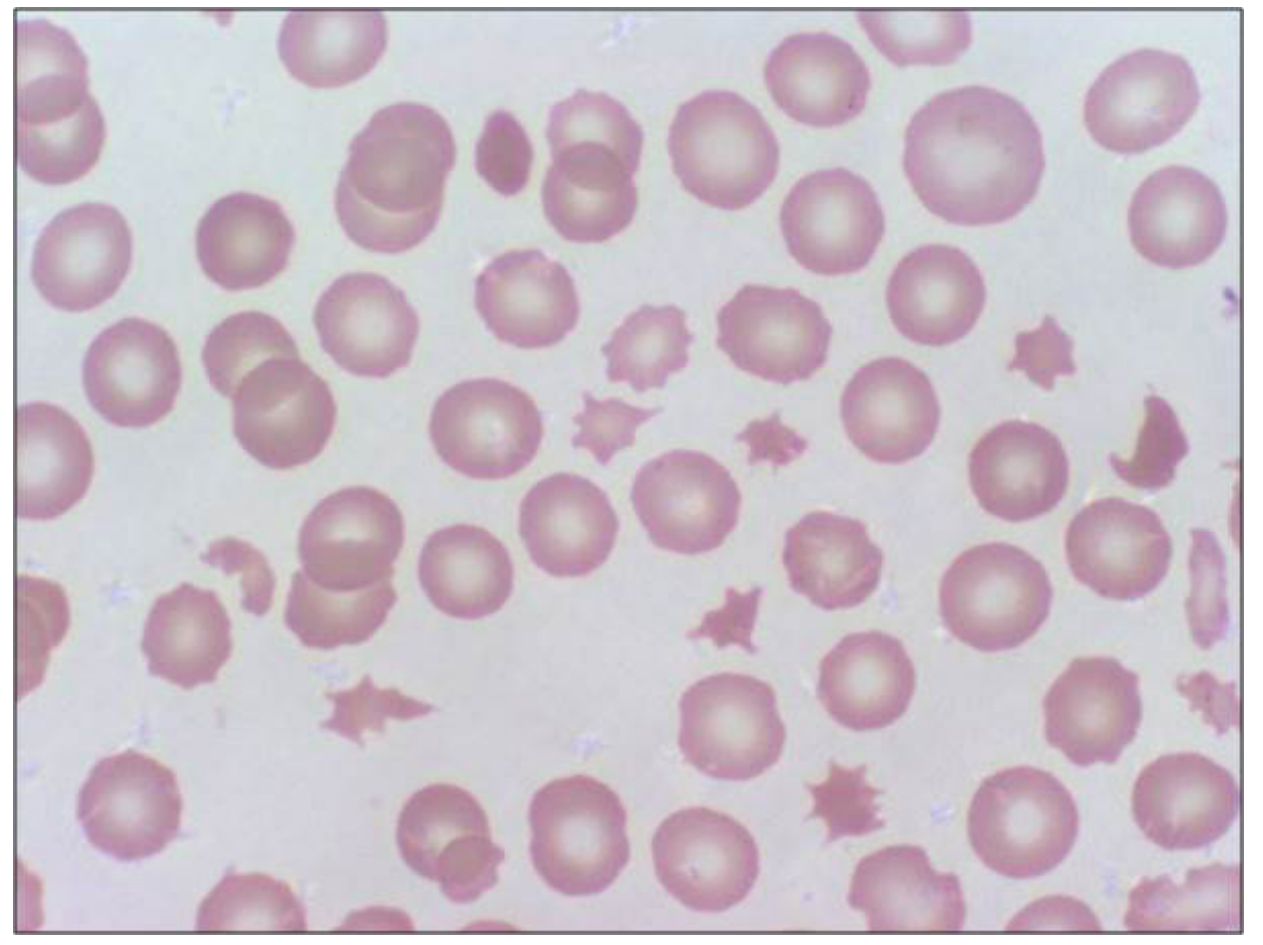

\subsubsection{Anemias raras debidas a trastornos del meta- bolismo de los factores de maduración}

Los trastornos metabólicos de los factores de maduración, todos ellos hereditarios, obedecen a mutaciones genéticas, en algunos casos desconocidas, que alteran el metabolismo del hierro o de las vitaminas (vitamina B12 y ácido fólico). Entre ellas destacan: a) la anemia sideroblástica congénita (ASC), debida a un defecto en la unión del hierro al grupo hemo, y b) la microcitosis congénita no sideroblástica, formada por un grupo de enfermedades muy raras y de descripción reciente que obedecen a defectos del metabolismo del hierro y cursan con anemia microcítica y sobrecarga de hierro.

\subsubsection{Anemia sideroblástica congénita (CSA)}

Son un grupo de trastornos que cursan con un porcentaje de sideroblastos "en anillo" en la médula ósea superior al 15\%. Los sideroblastos "en anillo" están formados por la disposición perinuclear de las mitocondrias que contienen grandes depósitos de hierro en su interior (véase figura 9).

La CSA microcítica obedece a mutaciones de genes que codifican paraproteínas implicadas en la ruta de biosíntesis de hemo: ALAS2 (OMIM 300751) y SLC25A38 (OMIN 205950) o en la biogénesis del clúster hierro-azu- fre: GLRX5 (OMIM 205950) y ABCB7 (OMIM 301310). En general cursan con una sobrecarga de hierro.

\subsubsection{Microcitosis congénita no sideroblástica}

Otras anemias hereditarias relacionadas con el metabolismo del hierro no presentan sideroblastos "en ani"lo", y se clasifican en cuatro grupos: aceruloplasminemia, atransferrinemia, anemia ferropénica refractaria al hierro (IRIDA) y déficit de DMT1. Todas estas enfermedades se heredan con carácter autosómico recesivo (Falco et al., 2013).

La aceruloplasminemia (OMIM 604290) es una rara enfermedad genética ligada a mutaciones de gen de la ceruloplasmina (CP), proteína plasmática que participa en la liberación de hierro al plasma partir de los macrófagos. Clínicamente, el déficit de CP cursa con anemia microcítica moderada, disminución del hierro en plasma con aumento de la ferritina y sobrecarga de hierro en el hígado, páncreas y ganglios basales. Suele asociarse a diabetes mellitus y a trastornos neurodegenerativos de aparición tardía. Su diagnóstico se basa en la demostración de una ausencia o concentración muy baja de CP y cobre en el plasma.

La atransferrinemia (OMIM 209300) obedece a una mutación del gen de la transferrina (TF), proteína 
Figura 9. Sideroblastos en anillo (eritroblastos con hierro intramitocondrial) en la anemia sideroblástica

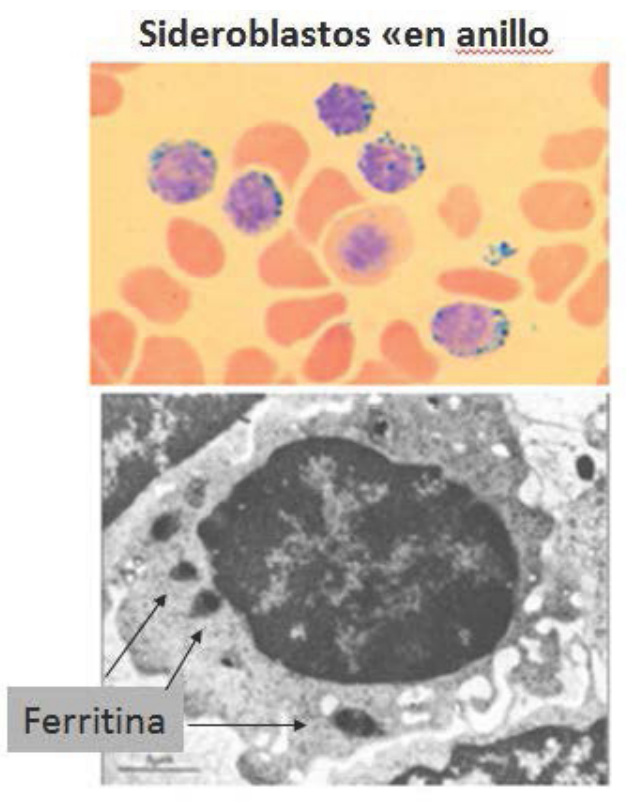

transportadora del hierro en la sangre. Clínicamente cursa con una anemia microcítica hipocrómica generalmente intensa y de inicio neonatal con sobrecarga de hierro hepática y en otros órganos vitales. Los signos externos son palidez y fatiga. Su diagnóstico de laboratorio se basa en la observación de valores muy bajos de TF sérica.

La anemia ferropénica refractaria al hierro (IRIDA, OMIM 206200) es una enfermedad rara ligada a mutaciones del gen TMPRSS6, que codifica la proteasamatriptasa-2, que producen un déficit de la misma. La disminución de matriptasa -2 se acompaña de una mayor producción de hepcidina, una hormona hepática que inhibe la absorción intestinal de hierro y dificulta la salida del hierro de los depósitos del organismo facilitando su acumulación. Clínicamente se caracteriza por una anemia hipocrómica microcítica de intensidad moderada que aparece hacia et tercer o cuarto mes de vida pero que no suele diagnosticarse hasta más tarde, incluso pasada la adolescencia.

El déficit de DMT1 (AHMIO1, OMIM 206100) es una forma de anemia microcítica que obedece a mutaciones del gen SLC11A2, que codifica el transportador de hierro DMT1 y regula su absorción y transferencia al citoplasma de los eritroblastos. Es una enfermedad ultra rara que no padecen más de cinco familias en todo el mundo. Clínicamente cursa con una anemia hipocroma y microcítica, en general muy intensa, y de

\section{Sideroacrersia en las mitocondrias}

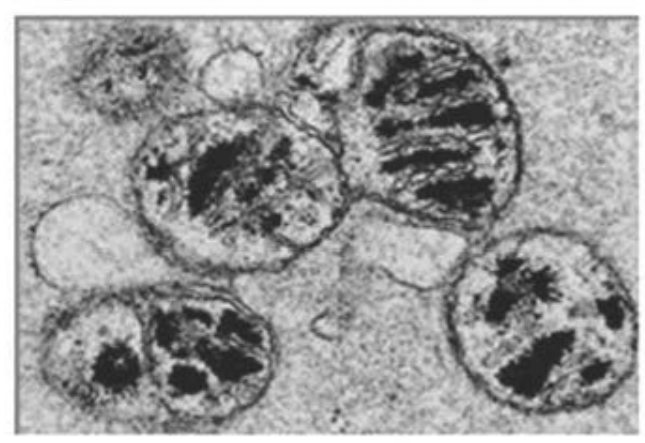

aparición perinatal que se acompaña de gran sobrecarga hepática de hierro.

\section{FALLOS MEDULARES HEREDITARIOS}

\subsection{Introducción a los fallos medulares hereditarios}

Los síndromes de fallo de la médula ósea congénitos o fallos medulares hereditarios (FMHs) son enfermedades multisistémicas que se caracterizan por presentar grados variables de deficiencia en la producción de células hematopoyéticas, que pueden ir desde la depleción de un solo linaje celular (citopenia) hasta la de múltiples linajes o incluso de todos los linajes (pancitopenia) (Dror, 2011; Shimamura y Alter, 2010). Los FMHs son enfermedades monogénicas con una alta heterogeneidad genética y solapamiento fenotípico entre sí por lo que se requiere un análisis tanto de médula ósea como genético para poder llegar a un diagnóstico correcto (Dokal y Vulliamy, 2010; Shimamura y Alter, 2010).

Son denominados síndromes raros por la muy baja prevalencia que presentan cada una de estas patologías. La incidencia conjunta estimada es de dos casos nuevos por un millón de individuos por año y de 65 casos por cada millón de recién nacidos vivos (Tsangaris et al., 2011). Suelen tener una presentación en la infancia, pero también se han descrito algunos casos en edad adulta. En todo caso, se asocian con morbilidad y mortalidad im- 
portante, requiriendo transfusiones sanguíneas de por vida, tratamiento de infecciones, factores de crecimiento y trasplante de progenitores hematopoyéticos. Así mismo, presentan alto riesgo de desarrollar cáncer hematológico o tumores sólidos y una alta toxicidad al tratamiento, lo que conlleva una menor esperanza de vida (Dror, 2011; Shimamura y Alter, 2010). En los siguientes apartados se describirán los aspectos más relevantes de algunos de estos síndromes.

\subsection{Anemia de Fanconi}

La anemia de Fanconi (AF; OMIM 227650) es una enfermedad hereditaria de patrón recesivo mayoritariamente autosómico y en un caso ligado al cromosoma X. Se trata de una enfermedad rara ya que su prevalencia en la población general se estima en dos a cinco casos por un millón de individuos, con una incidencia estimada de 1/131.000 nacimientos y una frecuencia de portadores sanos de 1/181 en los Estados Unidos de América (Rosenberg, Tamary y Alter, 2011).
Es importante tener en cuenta que la AF es responsable del $30 \%$ de los casos de niños con aplasia medular congénita (Shimamura y Alter, 2010) por lo que usualmente se debe sospechar AF cuando se está frente a un caso de aplasia medular congénita.

Hasta el momento se han identificado 21 genes implicados en AF cuyos nombres derivan de sus correspondientes grupos de complementación o subtipos genéticos (Bluteau et al., 2016) (véase tabla 2).

En la mayoría de los casos cada uno de los padres es portador de una de las variantes patogénicas, con tres excepciones: los pacientes varones del subtipo FA-B (gen $F A N C B$ ), los pacientes del subtipo FA-R (gen $R A D 51$ ) y en los casos en los cuales una de las dos variantes sea de novo (no presente en los padres o presente en solo algunos de los gametos de uno de los progenitores). El gen $F A N C B$ es un gen ligado al cromosoma $\mathrm{X}$, por lo que las mujeres son portadoras asintomáticas de la variante patogénica. El gen FANCR

Tabla 2. Subtipos genéticos y genes implicados en anemia de Fanconi

\begin{tabular}{|c|c|c|c|}
\hline $\begin{array}{l}\text { Subtipo/Grupo de } \\
\text { complementación }\end{array}$ & Gen AF & Localización cromosómica & Proteína \\
\hline A & FANCA & $16 q 24.3$ & FANCA \\
\hline B & FANCB & Xp22.31 & FANCB \\
\hline C & FANCC & $9 q 22.3$ & FANCC \\
\hline D1 & FANCD1/BRCA2* & $13 q 12.13$ & BRCA2 \\
\hline D2 & FANCD2 & $3 p 25.3$ & FANCD2 \\
\hline $\mathrm{E}$ & FANCE & $6 p 21-22$ & FANCE \\
\hline $\mathrm{F}$ & FANCF & $11 \mathrm{p} 15$ & FANCF \\
\hline G & FANCG & $9 p 13$ & FANCG \\
\hline 1 & $\mathrm{FANCI}$ & $15 q 25-26$ & $\mathrm{FANCl}$ \\
\hline J & FANCJ/BRIP1* & $17 q 22-24$ & BRIP1 \\
\hline L & FANCL & $2 \mathrm{p} 16.1$ & FANCL \\
\hline M & FANCM & $14 q 21.3$ & FANCM \\
\hline $\mathrm{N}$ & FANCN/ PALB2* & $16 \mathrm{p} 12.2$ & PALB2 \\
\hline 0 & FANCO/RAD51C* & $17 q 25.1$ & RAD51C \\
\hline $\mathrm{P}$ & FANCP/SLX4 & $16 \mathrm{p} 13.3$ & SLX4 \\
\hline Q & FANCQ/ERCC4 & $16 q 24.3$ & XPF \\
\hline $\mathrm{R}$ & FANCR/RAD51 & $15 q 15.1$ & RAD51 \\
\hline S & FANCS/BRCA1 & $17 q 21.31$ & BRCA1 \\
\hline $\mathrm{T}$ & FANCT/UBE2T & $7 q 36.1$ & UBE2T \\
\hline U & FANCU/XRCC2 & $7 q 36.1$ & XRCC2 \\
\hline V & FANCV/ REV7 & $1 p 36.22$ & MAD2L2 \\
\hline
\end{tabular}

*Genes cuyos defectos genéticos predisponen al desarrollo de cáncer en los portadores. 
(RAD51) ha sido descrito recientemente en un paciente AF (Ameziane et al., 2015), en quien se describe una variante de novo en heterocigosis simple con un efecto dominante negativo asociado a un fenotipo clínico y celular compatible con este síndrome. Mutaciones en cuatro de los genes FANC (FANCD1/BRCA2, FANCJ/BRIP1, FANCN/PALB2 y FANCO/RAD51C) también causan predisposición al cáncer de mama o de ovario en portadores asintomáticos.

Diversos estudios de carácter molecular coinciden en que los productos proteicos de estos genes actúan en diferentes niveles de una misma vía de reparación del DNA a la que han denominado ruta FA/BRCA (véase figura 10).

Hoy día se sabe que esta ruta consta de al menos tres complejos de proteínas claramente definidos, los cuales son indispensables para su activación y correcto funcionamiento con el fin de reparar un daño específico del DNA, como son los enlaces cruzados intercatenarios (ICLs, del inglés interstrand cross link).

Desde el punto de vista clínico, la AF está considerada como un síndrome de inestabilidad cromosómica con un alto espectro de manifestaciones clínicas que se pueden agrupar en malformaciones congénitas, disfunción endocrina, alteraciones hematológicas (ci- topenias, síndrome mielodisplasico (SMD) o leucemia mieloide aguda (LMA)), predisposición a desarrollar tumores y fragilidad cromosómica. Cabe destacar que un $30 \%$ de los pacientes no presenta malformaciones congénitas y solo son diagnosticados en el momento en que debuta la enfermedad con las alteraciones hematológicas (Shimamura y Alter, 2010). El 75\% de los pacientes presentan manifestaciones hematológicas en la primera década de vida (Kutler et al., 2003). Para hacer su diagnóstico se requiere de la confirmación por citogenética de la fragilidad cromosómica (Auerbach, 2009; Castellà et al., 2011a). La hipersensibilidad específica de las células AF a agentes inductores de ICLs, como el diepoxibutano (DEB) o la mitomicina $\mathrm{C}(\mathrm{MMC})$, ha permitido desarrollar un ensayo diagnóstico para la enfermedad estandarizado en linfocitos $T$ de sangre periférica (SP) (Auerbach, 2003). Este protocolo también se puede realizar, adaptándolo, en fibroblastos o amniocitos, dependiendo del caso que se esté estudiando. Además de este ensayo existen otros complementarios a la fragilidad cromosómica que permiten la caracterización genética de los pacientes con AF como son la parada del ciclo celular en fase G2/M, el análisis de monoubiquitinación de FANCD2 y el subtipaje de pacientes AF por complementación génica con vectores retrovirales.

Figura 10. Modelo de interconexión de la vías implicadas en fallos medulares hereditarios

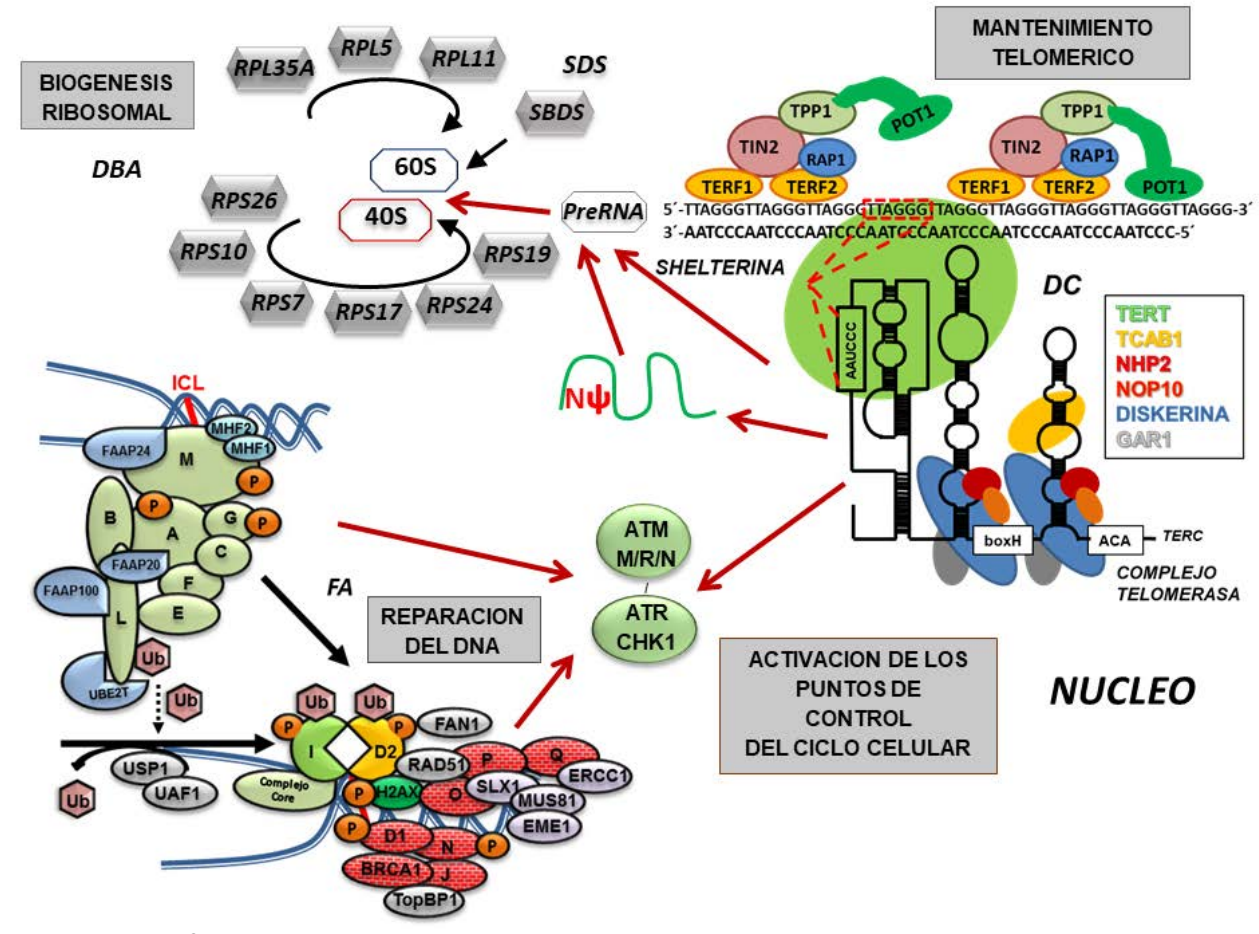

Fuente: Modificado del modelo propuesto por Dokal y Vulliamy, 2010. 
Hasta hace unos años el estudio genético no formaba parte del análisis clínico rutinario de los pacientes $A F$, en parte porque se consideraba como suficiente con la confirmación citogenética del diagnóstico (fragilidad cromosómica) y el subtipo del paciente y, por otra parte, porque el análisis mutacional resultaba laborioso. Sin embargo, con la implementación de nuevas tecnologías de secuenciación de alto rendimiento, actualmente se consigue realizar el subtipaje y el estudio mutacional a la vez, secuenciando todos los genes $\mathrm{AF}$ en un mismo ensayo, e incluso identificar nuevos genes implicados (Bogliolo et al., 2013). No obstante, esta aproximación de subtipar y buscar el gen en el mismo tiempo diagnóstico, puede provocar errores en estos pacientes, debido al amplio espectro mutacional de la enfermedad y a que no se han descrito aún todos los genes relacionados con la enfermedad. Por este motivo se aconseja que siempre se inicie el diagnóstico por el estudio mutacional en pacientes con una fragilidad cromosómica positiva para AF. Ante la identificación de variables de significado clínico incierto o de genes previamente no descritos como AF, se recomienda realizar un estudio funcional de complementación génica para ayudar a establecer la patogenicidad del gen identificado. En España el gen FAN$C A$ es el causante de un $77 \%$ del total de casos, con una mutación fundadora en la etnia gitana española/ portuguesa (96\% de los pacientes AF gitanos españoles presentan la mutación c.295C>T en homocigosis) (Callén et al., 2005; Castellà et al., 2011b). Con respecto a la población española no gitana se ha podido identificar una mayor frecuencia de tres mutaciones puntuales en los exones 13 (c.1115_1118delTTGG), 36 (c.3558insG) y 38 (c.3788_3790delTCT) de este gen que, junto con las grandes deleciones intragénicas, llegan a un $50 \%$ o $60 \%$ de las mutaciones observadas en FANCA (Castellà et al., 2011b).

Con respecto al tratamiento, además de corregir en lo posible algunas de las malformaciones congénitas, es indispensable hacer un seguimiento hematológico con el fin de identificar signos y síntomas tempranos de fallo de médula ósea (MO). Las actuales guías recomiendan el seguimiento de los recuentos sanguíneos cada tres a cuatro meses, y un aspirado de médula ósea anual. Se debe iniciar su tratamiento dependiendo del compromiso clínico del paciente y seguir con el mismo de acuerdo con la respuesta a este. Dentro de las medidas de soporte, se encuentran las transfusiones de concentrados de hematíes o plaquetas, el uso de factores estimulantes de colonias/citoquinas y el trasplante de progenitores hematopoyéticos. Este es actualmente el único tratamiento curativo para el fallo de médula ósea en estos pacientes. De todas maneras, el trasplante de progenitores hematopoyéticos no previene el desarrollo de cáncer en la AF y puede incluso ser un factor de riesgo para la aparición de tumores de cabeza y cuello en los casos en que aparezca enfermedad injerto contra huésped crónica (Shimamura y Alter, 2010). Independiente de si el paciente ha sido o no trasplantado, el seguimiento de riesgo oncológico, especialmente de carcinoma escamoso de cabeza y cuello, anal y ginecológico, es extremadamente importarte.

Finalmente, el diagnóstico correcto y precoz de la AF no solo permite descartar otras enfermedades, sino que fundamentalmente posibilita el manejo adecuado de sus alteraciones hematológicas y el consejo genético al individuo y su familia en caso de sucesivos embarazos. Además, en familias con mutaciones en genes de predisposición al cáncer, posibilita una adecuada vigilancia y evaluación del riesgo en familiares. Finalmente, el diagnóstico correcto de la enfermedad es imprescindible para el adecuado tratamiento de los tumores, debido al incremento de la toxicidad del tratamiento quimio y radioterápico en estos pacientes (Neveling, Endt, Hoehn y Schindler, 2009). En este sentido, el conocimiento de las bases moleculares de la enfermedad ha permitido personalizar los protocolos de acondicionamiento para el trasplante de progenitores hematopoyéticos en pacientes AF. Adicionalmente hoy en día es posible la selección preimplantacional de embriones sanos compatibles para curar al hermano afecto con el trasplante de progenitores hematopoyéticos (Verlinsky, Rechitsky, Schoolcraft, Strom y Kuliev, 2001). Finalmente hay que indicar que actualmente se están realizando en Estados Unidos y en España ensayos clínicos de terapia génica para curar la enfermedad (Tolar et al., 2011; Tremblay et al., 2013).

\subsection{Disqueratosis Congénita}

Esta patología (OMIM 305000, 127550, 224230) es considerada la segunda causa de anemia aplásica congénita. Aunque fue considerada inicialmente como solo una displasia ectodérmica (denominada síndrome de Zinsser-Cole-Engman), posteriormente fue relacionada con anomalías hematológicas, y mejor caracterizada mediante estudios funcionales y genéticos (Shimamura y Alter, 2010).

Se trata de una enfermedad rara con múltiples patrones de herencia: autosómico recesivo, autosómico dominante o ligado al cromosoma X. Se observa una mayor afectación de varones, con una relación 
hombre:mujer de 3:1, estimada a partir de 550 casos descritos en la bibliografía (Shimamura y Alter, 2010). Con respecto a su expresión clínica, se ha descrito una tríada diagnóstica dada por distrofia ungueal, pigmentación poiquilodérmica y leucoplasia de la mucosa oral, pero solo un $46 \%$ de los pacientes suelen presentarla. Estas anomalías suelen estar presentes en los afectados por separado con un $70 \%$ para las dos primeras y un $47 \%$ para la última. De todos modos, el $75 \%$ de los pacientes con disqueratosis congénita (DC) presentan por lo menos una de estas manifestaciones u otra anomalía congénita.

Hay dos subgrupos de DC muy graves. El síndrome de Hoyeraal-Hreidarsson (HH, MIM 300240), caracterizado por hipoplasia cerebelosa, ataxia, retraso en el desarrollo psicomotor, microcefalia, inmunodeficiencia, retraso del crecimiento intrauterino y anemia aplásica grave, que debuta a edad temprana. El síndrome de Revesz (RS, MIM 268130), caracterizado por retinopatía exudativa bilateral, retardo del crecimiento intrauterino, desarrollo de anemia aplásica y calcificaciones a nivel del sistema nervioso central (Dokal y Vulliamy, 2008; Shimamura y Alter, 2010).

El diagnóstico clínico de esta patología suele realizarse a una edad media de 14 años, con un rango de edad que va desde el nacimiento hasta los 75 años. Los individuos afectados por DC no presentan un aumento de la incidencia de aplasia medular en la infancia. Sí se ha visto que el riesgo de padecer esta última se ve incrementado en un $1 \%$ cada año hasta los 20 años, y hasta en un $10 \%$ cada año hasta los 50 años. De manera similar a como ocurre en la $A F$, la incidencia acumulada de aplasia medular es del $50 \%$ a los 50 años. El fallo de la médula ósea es la complicación más frecuente en niños, mientras que la fibrosis pulmonar es la causa de mortalidad más frecuente en adultos (Parry, Alder, Qi, Chen y Armanios, 2011). La mediana de edad de los pacientes que han sobrevivido sin ser diagnosticados de ningún cáncer en la bibliografía es de 68 años, muy superior a la de los pacientes diagnosticados de AF. En esta etapa de la vida es más frecuente el cáncer de tipo sólido (Dokal y Vulliamy, 2010; Shimamura y Alter, 2010).

El acortamiento acelerado de los telómeros es la característica molecular de este síndrome que genera la disfunción o muerte celular. Esto se explica porque los genes implicados en el desarrollo de esta enfermedad tienen como finalidad el mantenimiento y la estabilidad telomérica (véase figura 10). No obstante, hay un $40 \%$ de pacientes sin mutaciones en estos genes (Dokal y Vulliamy, 2010; Wegman-Ostrosky y Savage,
2017; Shimamura y Alter, 2010) (Véase tabla 3). En España los estudios mutacionales han identificado tres familias ligadas al cromosoma $\mathrm{X}$ con mutaciones en $D K C 1$ y cuatro familias con patrón autosómico dominante y con mutaciones en TERT (Carrillo et al., 2012).

Los telómeros son regiones repetitivas en tándem TTAGGG localizadas en los extremos de los cromosomas, con una función especializada en facilitar la replicación del DNA terminal y prevenir alteraciones cromosómicas que son producto de sus extremos libres (reordenamientos como deleciones, duplicaciones, etc.). Estas secuencias repetitivas se asocian con un complejo proteico denominado Shelterina, que cumple su función de protección y mantenimiento telomérico. Durante el proceso replicativo del DNA, la enzima telomerasa da lugar a estas secuencias teloméricas en el extremo 3'-hidroxilo mediante el RNA $T E R C$ usado como molde (véase figura 10). Ante niveles limitados de telomerasa se van acortando secuencialmente estas regiones teloméricas con cada división celular (Calado y Young, 2009; Dokal y Vulliamy, 2010; Shimamura y Alter, 2010).

El diagnóstico se basa en la identificación de los hallazgos clínicos patognomónicos de la DC (triada clínica) asociados a anomalías hematológicas y a cáncer. Sin embargo, dado que muchos pacientes no presentan anomalías clínicas características, es imprescindible que ante una aplasia medular que no responde a tratamiento inmunosupresor, y en la que se ha descartado $A F$, se realice una prueba que permita excluir el diagnóstico. Ya hemos visto que, en la AF, el estudio de inestabilidad cromosómica permite el diagnóstico en el laboratorio. En el caso de la DC la prueba recomendada para confirmar el diagnóstico será el análisis de la longitud de los telómeros en células de sangre periférica (Dokal y Vulliamy, 2010; Shimamura y Alter, 2010; Vulliamy et al., 2004).

Se ha descrito que importantes acortamientos teloméricos, por debajo de una longitud crítica, activan la senescencia replicativa y limitan el potencial proliferativo celular. Esto se explicaría porque los tejidos del sistema hematopoyético y la mucosa epitelial, que en condiciones normales presentan una alta tasa proliferativa, están clínicamente más afectados en la DC (Dokal y Vulliamy, 2010; Shimamura y Alter, 2010).

Entre las características clínicas de esta patología está el fenómeno de anticipación. La anticipación consiste en que a medida que la enfermedad va pasando de generación en generación esta aparece a edad más temprana, con 
Tabla 3. Subtipos genéticos y genes implicados en la disqueratosis congénita

\begin{tabular}{|c|c|c|c|c|}
\hline Patrón de herencia & $\%$ pacientes & Locus & Gen & Proteína \\
\hline RLX & $17-36$ & Xq28 & $D K C 1$ & Disqueratina \\
\hline$A D$ & $\begin{array}{c}5 \\
5 \\
11-24 \\
5-10 \\
<1\end{array}$ & $\begin{array}{l}3 q 26 \\
5 p 15 \\
14 q 11 \\
20 q 13.3 \\
16 p 13.12\end{array}$ & $\begin{array}{l}\text { TERC } \\
\text { TERT } \\
\text { TINF2 } \\
\text { RTEL1 } \\
\text { PARN }\end{array}$ & $\begin{array}{l}\text { TERC } \\
\text { TERT } \\
\text { TIN2 } \\
\text { RTEL1 } \\
\text { PARN }\end{array}$ \\
\hline AR & $\begin{array}{c}<1 \\
1 \\
<1 \\
<1 \\
<1 \\
<1 \\
<1 \\
<1 \\
<1\end{array}$ & $\begin{array}{l}15 q 14 \\
5 p 15 \\
5 q 35 \\
17 p 13.1 \\
17 p 13.1 \\
16 q 22.1 \\
16 p 13.1220 q 13.3\end{array}$ & $\begin{array}{l}\text { NOP10/NOLA3 } \\
\text { TERT } \\
\text { NHP2/ NOLA2 } \\
\text { WRAP53 /TCAB1 } \\
\text { ACD } \\
\text { CTC1 } \\
\text { PARN } \\
\text { RTEL1* }\end{array}$ & $\begin{array}{l}\text { NOP10 } \\
\text { TERT } \\
\text { NHP2 } \\
\text { WRAP53 } \\
\text { ACD } \\
\text { CTC1 } \\
\text { PARN } \\
\text { RTEL1 }\end{array}$ \\
\hline Desconocido & $\begin{array}{l}\text { Desconocido } \\
\text { Desconocido }\end{array}$ & $\begin{array}{l}10 q 24.33 \\
4 q 32.2\end{array}$ & $\begin{array}{l}\text { STN1 } \\
\text { NAF1 }\end{array}$ & $\begin{array}{l}\text { STN1 } \\
\text { NAF1 }\end{array}$ \\
\hline No caracterizada & $\sim 40$ & - & - & - \\
\hline
\end{tabular}

RLX: recesivo ligado al $X, A D$ : autosómico dominante, AR: autosómico recesivo.

Fuente: Basado en Wegman-Ostrosky y Savage, 2017; Shimamura y Alter, 2010; Savage, 2013; Walne, Vulliamy, Kirwan, Plagnol y Dokal, 2013.

mayor gravedad del fenotipo clínico y asociado a telómeros cada vez más cortos. Este fenómeno ha sido descrito en las generaciones sucesivas de familias con mutaciones en TERC, TERT y TINF2 (Armanios et al., 2005; Fernández García y Teruya-Feldstein, 2014; Vulliamy et al., 2004).

En cuanto al manejo médico de la DC es parecido al de la AF y depende del compromiso clínico del paciente. Incluye el tratamiento de infecciones, el uso de factores estimulantes de colonias/citoquinas y el trasplante de progenitores hematopoyéticos en casos de aplasia medular grave. El trasplante de progenitores hematopoyéticos es el tratamiento curativo para el fallo medular pero no cura la enfermedad en otros tejidos. Además el régimen de acondicionamiento para el trasplante de progenitores hematopoyéticos puede exacerbar la fibrosis pulmonar, por lo que se recomienda la medición de la función pulmonar anualmente en estos pacientes (Dokal y Vulliamy, 2008; Shimamura y Alter, 2010).

\subsection{Anemia de Diamond-Blackfan}

A diferencia de otros síndromes de fallo medular congénito, en que la descripción inicial ya consideraba características propias del síndrome además del fallo medular, como las malformaciones congénitas, en la anemia de Diamond Blackfan (ADB; OMIM 105650) la primera descripción solo describía una anemia pura neonatal que requirió soporte transfusional. Actualmente ya han sido descritos en la bibliografía cerca de 1.000 casos, y aproximadamente el $25 \%$ de ellos presentan al menos una anomalía congénita. La ADB es una enfermedad rara con patrón de herencia autosómico dominante. No se han observado diferencias entre varones y mujeres (relación 1:1). La baja talla es la anomalía más frecuente seguida de las alteraciones en el pulgar. Se han descrito otras anomalías menos frecuentes, tales como las alteraciones craneofaciales, el labio leporino, el paladar hendido y el cuello corto (Dokal y Vulliamy, 2008; Tsangaris et al., 2011). La edad media para el diagnóstico es de tres meses, con un rango que va desde el nacimiento hasta los 64 años de edad, siendo el $98 \%$ de los casos diagnosticados en el primer año de vida (Dokal y Vulliamy, 2010; Shimamura y Alter, 2010).

La ADB tiene su base molecular en mutaciones heterocigotas en los genes que codifican los componentes de cualquiera de las subunidades ribosomales tanto pequeña $40 S$ como grande $60 S$ (véase tabla 4 y figura 10).

Las mutaciones en estos genes afectan el procesamiento del RNA ribosómico. Recientemente se ha relacionado también la ADB con mutaciones en el factor de transcripción GATA-1 (Parrella et al., 2014), en 
Tabla 4. Subtipos genéticos y genes implicados en la anemia de Diamond-Blackfan.

\begin{tabular}{|c|c|c|c|c|}
\hline Subtipo DC & $\%$ pacientes & Locus & Gen & Proteína \\
\hline$A D$ & 25 & $19 q 13.2$ & RPS19 & RPS19 \\
\hline$A D$ & 2 & $10 q 22-23$ & RPS24 & RPS24 \\
\hline$A D$ & 1 & $15 q 25.2$ & RPS17 & RPS17 \\
\hline$A D$ & 7 & $1 \mathrm{p} 22.1$ & RPL5 & RPL5 \\
\hline$A D$ & 5 & $1 p 36.11$ & RPL11 & RPL11 \\
\hline$A D$ & 3 & $3 q 29$ & RPL35A & RPL35A \\
\hline$A D$ & 1 & $2 p 25.3$ & RPS7 & RPS7 \\
\hline$A D$ & 7 & $6 \mathrm{p} 21.31$ & RPS10 & RPS10 \\
\hline$A D$ & 3 & $12 q 13$ & RPS26 & RPS26 \\
\hline$A D$ & $<1$ & 17p13.1 & RPL26 & RPL26 \\
\hline$A D$ & $<1$ & $14 q 21.3$ & RPS29 & RPS29 \\
\hline$A D$ & $<1$ & $18 q 21.1$ & RPL17 & RPL17 \\
\hline$A D$ & $<1$ & $3 p 24.2$ & RPL15 & RPL15 \\
\hline$A D$ & $<1$ & 17p13.1 & RPL26 & RPL26 \\
\hline$A D$ & $<1$ & $17 q 12$ & RPL19 & RPL19 \\
\hline$A D$ & $<1$ & $2 q 11.2$ & RPL31 & RPL31 \\
\hline$A D$ & $<1$ & $8 q 12.1$ & RPS20 & RPS20 \\
\hline$A D$ & $<1$ & 19p13.2 & RPS28 & RPS28 \\
\hline LX & $<1$ & Xp11.23 & GATA-1 & GATA1 \\
\hline Desconocido & $\sim 40$ & - & - & - \\
\hline
\end{tabular}

Fuente: Basado en Dokal y Vulliamy, 2010; Landowski et al., 2013; Mirabello et al., 2014; Wegman-Ostrosky y Savage, 2017.

RPS29 (Mirabello et al., 2014) y en RPL15 (Landowski et al., 2013). Alrededor del $45 \%$ de los pacientes con ADB carecen de mutaciones en estos genes identificados, tal como se muestra en la tabla 4 (Dokal y Vulliamy, 2010; Wegman-Ostrosky y Savage, 2017; Mirabello et al., 2014; Ruggero y Shimamura, 2014).

El diagnóstico de ADB desde el punto de vista clínico es complejo. Los recuentos sanguíneos generalmente muestran una anemia macrocítica con reticulocitopenia, así como la $\mathrm{Hb}$ F y la adenosina desaminasa eritrocitaria elevadas en más de $85 \%$ de los pacientes. En la médula ósea encontraremos de manera característica una eritroblastopenia profunda sin alteración del resto de líneas celulares. Sin embargo, pueden ser descritas alteraciones menores en la línea mieloide o en los megacariocitos. El principal diagnóstico diferencial debe realizarse con la eritroblastopenia transitoria de la infancia, aunque otros FMH deben tenerse también presentes (Shimamura y Alter, 2010).
La incidencia acumulada para SMD, LMA y algunos tumores sólidos (osteosarcoma, linfoma de Hodgking) ha sido estimada en un $20 \%$ a los 46 años, lo que implica un aumento del riesgo de desarrollar cáncer. El seguimiento en el tiempo de los casos de cáncer (leucemia o un tumor sólido) sugiere una sobrevida libre de cáncer de más del $50 \%$ en los pacientes a los 40 años (Vlachos, Rosenberg, Atsidaftos, Alter y Lipton, 2012).

El tratamiento se basa en la respuesta de gran número de pacientes a los esteroides. Sin embargo, se aconseja no realizar este tratamiento hasta pasado el primer año de edad. Hasta entonces, y en aquellos pacientes que no responden a los esteroides, o que los precisan a dosis muy altas, el único tratamiento será el soporte transfusional adecuado con concentrados de hematíes. El único tratamiento curativo de la enfermedad es el trasplante de progenitores hematopoyéticos, aunque hasta este momento se desaconseja 
si no existe un donante familiar HLA idéntico (Dror, 2011; Shimamura y Alter, 2010).

Es probable que los defectos genéticos en esta patología aceleren la apoptosis de las células progenitoras eritroides, ya que se ha demostrado que MDM2 (un regulador central de p53 que actúa como una ubiquitina ligasa que conduce a la degradación de p53) se une específicamente a varias proteínas ribosomales libres, incluyendo RPL5, RPL23, RPL11, RPS7, y RPL26. Una hipótesis alternativa o complementaria implica un desequilibrio entre la producción de hemo y globina lo que conduciría a eritropoyesis ineficaz, apoptosis y anemia (Narla y Ebert, 2010).

\subsection{Síndrome de Shwachman-Diamond}

La primera descripción del síndrome de Shwachman-Diamond (SDS, MIM 260400) se debió a la observación de que varios niños con mala absorción por insuficiencia pancreática también presentaban neutropenia. Aunque la herencia es autosómica recesiva, hay un mayor número de casos masculinos con una ratio hombre:mujer de 1.48:1 (Shimamura y Alter, 2010). La frecuencia de portadores se ha estimado en $0,0036 \%$ y la incidencia en 1 en 76.563 nacidos vivos para la población estadounidense (Goobie et al., 2001).

En un $55 \%$ de los 560 casos descritos se observan anomalías físicas. La baja estatura es la anomalía más frecuente (en un 50\%), seguida por la disostosis metafisiaria documentada radiográficamente (en un 25\%), y por anomalías torácicas y retraso en el desarrollo. La edad media diagnóstica a la que se detecta la mala absorción está en dos semanas de edad, con un rango que va desde el nacimiento hasta los 11 años. La neutropenia habitualmente se observa algo más tarde, lo que puede retardar en algunos casos la edad de diagnóstico, que se basa esencialmente en la combinación de la disfunción pancreática exocrina más un signo de fallo de la médula ósea (Dokal y Vulliamy, 2008; Shimamura y Alter, 2010).

La disfunción pancreática es otro síntoma que debe sospecharse cuando se muestran heces grasas. La insuficiencia pancreática exocrina debe ser confirmada mediante la cuantificación de las enzimas duodenales o el análisis de grasa en heces. Actualmente está recomendada la determinación en suero de los niveles de tripsinógeno e isoamilasa pancreática (Rothbaum et al., 2002).

Desde el punto de vista hematológico, se deben documentar las neutropenias de repetición, asociadas en ocasiones a anemia, macrocitosis, $\mathrm{Hb}$ F elevada o trombocitopenia. En algunas ocasiones el análisis de la médula ósea puede mostrar hipocelularidad, con una depleción de precursores mieloides. La anemia aplásica puede estar presente hasta en un $20 \%$ de los pacientes con una mediana de edad de tres años (rango que va desde el nacimiento hasta los 35 años). Entre las complicaciones hematológicas más graves del SDS está el SMD y la LMA con una edad media de ocho años en el momento del diagnóstico (rango que va desde los seis meses a los 42 años) (Dokal y Vulliamy, 2008; Shimamura y Alter, 2010).

Con respecto a su etiología genética, hasta en un $90 \%$ de los pacientes con SDS se identifican mutaciones bialélicas en el gen SBDS (locus 7q11), que está altamente conservado en el aspecto de la evolución. Codifica la proteína SBDS, con una expresión de $m$ RNA de forma ubicua. Esta proteína multifuncional se ha implicado en la biogénesis de ribosomas (véase figura 10), en el procesamiento del RNA y en la estabilización del huso mitótico (Ceci et al., 2003; Moore, Farrar, Arceci, Liu y Ellis, 2009).

Las principales causas de mortalidad en SDS son las complicaciones hematológicas de insuficiencia medular y el desarrollo de cáncer. En aquellos pacientes con neutropenias graves hay mayor riesgo de infecciones. Por lo tanto, el manejo médico depende de la evolución clínica, requiriendo tratamiento específico de las infecciones, y suele incluir el uso de factores estimulantes de colonias/citoquinas. Además de lo ya mencionado, los pacientes con SDS pueden requerir transfusiones sanguíneas para el manejo de las citopenias. El trasplante de progenitores hematopoyéticos está indicado para fallos de médula ósea graves, SMD, LMA o citopenias refractarias a los otros tratamientos (Dokal y Vulliamy, 2008; Shimamura y Alter, 2010).

\subsection{Otros fallos medulares hereditarios}

Existen otros síndromes sin comentar que forman parte de esta categoría, como es el caso de la neutropenia congénita severa, la trombocitopenia amegacariocítica, la trombocitopenia con ausencia de radio o la deficiencia de GATA2, entre otros (Wegman-Ostrosky y Savage, 2017). Se trata de síndromes menos frecuentes pero que se deben tener en cuenta como diagnóstico diferencial frente a un caso con aplasia medular de tipo congénito. Por otra parte, el solapamiento clínico refleja cierto grado de interconexión entre las rutas moleculares que están implicadas en el fallo de médula ósea y la íntima relación de estas vías con la regulación del ciclo celular, la estabilidad 
genómica y la apoptosis, tal como se intenta ilustrar en la figura 10.

El hemograma y el espectro de malformaciones congénitas pueden ayudar a establecer el diagnóstico, pero el grado de solapamiento fenotípico limita un correcto diagnóstico basado exclusivamente en manifestaciones clínicas, por lo que el diagnóstico diferencial basado en estudios funcionales y genéticos suele ser determinante. Estos estudios se ven dificultados por el hecho de que los genes implicados en los diversos FMH son muy numerosos y, por tanto, es previsible que las nuevas técnicas de secuenciación masiva se vayan implantando paulatinamente en la rutina diagnóstica. Esto permitirá ahorrar tiempo y dinero en la caracterización genética de enfermedades raras con alta heterogeneidad genética como son los $\mathrm{FMH}$. Una alternativa ya utilizada en algunos $\mathrm{FMH}$ como la AF es el uso de paneles dirigidos a la captura y secuenciación masiva de los genes implicados. Otra opción es recurrir a la secuenciación masiva del exoma completo que puede ser útil no solo para caracterizar las mutaciones sino también para identificar nuevos genes en pacientes sin mutaciones en los genes ya conocidos (Bogliolo et al. 2013).

\subsection{Conclusión}

Un conocimiento más profundo de estas patologías permitirá en un futuro comprender mejor la fisiopatología de la hematopoyesis con el fin de brindar un adecuado manejo clínico a los pacientes que padecen estos trastornos genéticos. Además, como estas patologías se asocian generalmente con malformaciones congénitas y predisposición a desarro- llar algún tipo de cáncer, su comprensión también proporcionará conocimientos sobre el desarrollo embrionario humano y sobre el origen de los tumores (Dokal y Vulliamy, 2010).

\section{AGRADECIMIENTOS}

El grupo del profesor Joan Lluis Vives Corrons, perteneciente al Hospital Clinic de la Univerrsidad de Barcelona (IDIBAPS), ha recibido financiación de la Comisión Europea (European Comission for Rare Diseases. Directorate of Public Health SANCO) para el Proyecto European Network for Rare and Congenital Anaemias (ENERCA 2002-2016; Ref 2012/12/17) y de la Marato de TV3 (Fundació la Marato de TV3) para el Proyecto Creation of a Catalan Network for the Diagnosis and Clinical Management of Rare Anaemias due to major haemoglobinopathies (2011- 2014 Fundacio la Marato de TV3; Ref 101730/101731). Durante el año 2013 se obtuvo financiación del CIBERER para desarrollar, en colaboración con el CIEMAT (profesor J. C. Segovia) un proyecto de investigación sobre déficit hereditario de piruvato-cinasa eritrocitaria (PK) en España. El grupo del profesor Jordi Surrallés está financiado por la Generalitat de Catalunya (SGR0489-2009; SGR03172014), el premio ICREA-Academia, la Marato de TV3 (464/C/2012), el Ministerio de Economía y Competitividad (CIBERER CB06/07/0023 y SAF2012-31881), el Ministerio de Sanidad (FANCOSTEM, FANCOLEN), la Comisión Europea (EUROFANCOLEN HEALTHF5-2012-305421) y Fondos FEDER. EI CIBERER es una iniciativa del Instituto de Salud Carlos III.

\section{BIBLIOGRAFÍA}

Ameziane, N., May, P., Haitjema, A., Vrugt, H. J. van de, Rossum-Fikkert, S. E. van, Ristc, D. [...] y Rooimans, M. A. (2015). A novel Fanconi anaemia subtype associated with a dominantnegative mutation in RAD51. Nature Communications, 6, 8829.

Armanios, M., Chen, J.-L., Chang, Y.-P.C., Brodsky, R. A., Hawkins, A., Griffin, C. A. [...] y Greider, C. W. (2005). Haploinsufficiency of telomerase reverse transcriptase leads to anticipation in autosomal dominant dyskeratosis congenita. Proceedings of the National Academy of Sciences of the United States of America, 102 (44), pp. 15960-15964.

Auerbach, A. D. (2003). Diagnosis of Fanconi anemia by diepoxybutane analy- sis. Current Protocols in Human Genetics, 37 (1), pp. 8.7.1-8.7.15.

Auerbach, A. D. (2009). Fanconi anemia and its diagnosis. Mutation Research / Fundamental and Molecular Mechanisms of Mutagenesis, 668 (1), pp. 4-10.

Bain, B. J. (2005). Diagnosis from the blood smear. New England Journal of Medicine, 353 (5), 498-507.

Bain, B. J. (2011). Haemoglobinopathy diagnosis: algorithms, lessons and pitfalls. Blood Reviews, 25 (5), pp. 205-213.

Bianchi, P., Fermo, E. y Zanella, A. (2012). Reply to "Flow cytometry test for hereditary spherocytosis". Haematologica, 97 (12), e50-e51.
Bluteau, D., Masliah-Planchon, J., Clairmont, C., Rousseau, A., Ceccaldi, R., Dubois d'Enghien, C. [...] y Leblanc, T. (2016). Biallelic inactivation of REV7 is associated with Fanconi anemia. The Journal of Clinical Investigation, 126 (9), pp. 3580-3584.

Bogliolo, M., Schuster, B., Stoepker, C., Derkunt, B., Su, Y., Raams, A. [...] y Casado, J. A. (2013). Mutations in ERCC4, Encoding the DNA-Repair Endonuclease XPF, Cause Fanconi Anemia. The American Journal of Human Genetics, 92 (5), pp. 800-806.

Calado, R. T. y Young, N. S. (2009). Telomere diseases. New England Journal of Medicine, 361 (24), pp. 2353-2365. 
Callén, E., Casado, J. A., Tischkowitz, M. D., Bueren, J. A., Creus, A., Marcos, R. [...] y Winter, J. de. (2005). A common founder mutation in FANCA underlies the world's highest prevalence of Fanconi anemia in Gypsy families from Spain. Blood, 105 (5), pp. 1946-1949.

Carrillo, J., Martínez, P., Solera, J., Moratilla, C., González, A., Manguán-García, C. [...] y Escoda, L. (2012). High resolution melting analysis for the identification of novel mutations in DKC1 and TERT genes in patients with dyskeratosis congenita. Blood Cells, Molecules and Diseases, 49 (3-4), pp. 140-146.

Castellà, M., Pujol, R., Callén, E., Ramírez, M. J., Casado, J. A., Talavera, M. [...] y Cela, E. (2011a). Chromosome fragility in patients with Fanconi anaemia: diagnostic implications and clinical impact. Journal of Medical Genetics, 48 (4), pp. 242-250.

Castellà, M., Pujol, R., Callén, E., Trujillo, J. P., Casado, J. A., Gille, H. [...] y Surrallés, J. (2011b). Origin, functional role and clinical impact of Fanconi anemia FANCA mutations. Blood, 117, 3759-3769.

Ceci, M., Gaviraghi, C., Gorrini, C., Sala, L. A., Offenhauser, N., Carlo Marchisio, P. y Biffo, S. (2003). Release of elF6 (p27 BBP) from the 60S subunit allows $80 \mathrm{~S}$ ribosome assembly. Nature, 426 (6966), pp. 579-584.

Dacie, S. J. (2001). The immune haemolytic anaemias: A century of exciting progress in understading. British Journal of Haematology, 114 (4), pp. 770-785.

Dokal, I. y Vulliamy, T. (2008). Inherited aplastic anaemias/bone marrow failure syndromes. Blood Reviews, 22 (3), pp. 141-153.

Dokal, I. y Vulliamy, T. (2010). Inherited bone marrow failure syndromes. Haematologica, 95 (8), 1236-1240.

Dror, Y. (2011). Genetic Basis of Inherited Bone Marrow Failure Syndromes. En Ikehara, K. (ed.). Advances in the Study of Genetic Disorders, pp. 357-392.

Falco L. de, Sánchez M., Silvestri, L., Kannengiesser, C., Muckenthaler, M. U., Iolascon, A. [...] y Beaumont, C. (2013). Iron refractory iron deficiency anemia. Haematologica, 98 (6), pp. 845-853.
Fernández García, M. S. y Teruya-Feldstein, J. (2014). The diagnosis and treatment of dyskeratosis congenita: a review. Journal of Blood Medicine, 5, pp. 157-167.

Goobie, S., Popovic, M., Morrison, J., Ellis, L., Ginzberg, H., Boocock, G.R.B. [...] y Hudson, T. J. (2001). Shwachman-Diamond Syndrome with Exocrine Pancreatic Dysfunction and Bone Marrow Failure Maps to the Centromeric Region of Chromosome 7. The American Journal of Human Genetics, 68 (4), pp. 1048-1054.

Iolascon, A., Heimpel, H., Wahlin, A. y Tamary, H. (2013). Congenital dyserythropoietic anemias: molecular insights and diagnostic approach. Blood, 122 (13), pp. 2162-2166.

Kedar, P. S., Colah, R. B., Kulkarni, S., Ghosh, K. y Mohanty, D. (2003). Experience with eosin-5'-maleimide as a diagnostic tool for red cell membrane cytoskeleton disorders. Clinical \& Laboratory Haematology, 25 (6), 373-376.

King, M. J. y Zanella, A. (2013). Hereditary red cell membrane disorders and laboratory diagnostic testing. International Journal of Laboratory Hematology, 35 (3), 237-243.

Kutler, D. I., Singh, B., Satagopan, J., Batish, S. D., Berwick, M., Giampietro, P. F. [...] y Auerbach, A. D. (2003). A 20year perspective on the International Fanconi Anemia Registry (IFAR). Blood, 101 (4), pp. 1249-1256.

Landowski, M., O'Donohue, M. F., Buros, C., Ghazvinian, R., Montel-Lehry, N., Vlachos, A. [...] y Gazda, H. T. (2013). Novel deletion of RPL15 identified by array-comparative genomic hybridization in DiamondBlackfan anemia. Human Genetics, 132 (11), pp. 1265-1274.

Luzzatto, L. y Seneca, E. (2014). G6PD deficiency: A classic example of pharmacogenetics with on-going clinical implications. British Journal of Haematology, 164 (4), pp. 469-480.

Mirabello, L., Macari, E. R., Jessop, L., Ellis, S. R., Myers, T., Giri, N. [...] y Savage, S. A. (2014). Whole-exome sequencing and functional studies identify RPS29 as a novel gene mutated in multicase Diamond-Blackfan anemia families. Blood, 124, pp. 24-32.
Moore, J. B., Farrar, J. E., Arceci, R. J., Liu, J. M. y Ellis, S.R. (2009). Distinct ribosome maturation defects in yeast models of Diamond-Blackfan anemia and Shwachman-Diamond syndrome. Haematologica, 95, pp. 57-64.

Narla, A. y Ebert, B. L. (2010). Ribosomopathies: human disorders of ribosome dysfunction. Blood, 115, pp. 3196-3205.

Neveling, K., Endt, D., Hoehn, H. y Schindler, D. (2009). Genotype-phenotype correlations in Fanconi anemia. $\mathrm{Mu}$ tation Research/Fundamental and Molecular Mechanisms of Mutagenesis, 668 (1), pp. 73-91.

Noris, M. y Remuzzi, G. (2009). Atypical Hemolytic-Uremic Syndrome". New England Journal of Medicine, 361 (17), pp. 1676-1687.

Parker, C. J. (2012). Paroxysmal nocturnal hemoglobinuria. Current Opinion in Hematology, 19 (3), pp. 141-148.

Parrella, S., Aspesi, A., Quarello, P., Garelli, E., Pavesi, E., Carando, A. [...] y Dianzani, I. (2014). Loss of GATA-1 full length as a cause of Diamond-Blackfan anemia phenotype. Pediatric Blood \& Cancer, 61 (7), pp. 1319-1321.

Parry, E. M., Alder, J. K., Qi, X., Chen, J. J. y Armanios, M. (2011). Syndrome complex of bone marrow failure and pulmonary fibrosis predicts germline defects in telomerase. Blood, 117, pp. 5607-5611.

Pasricha, S.-R. (2014). Anemia: a comprehensive global estimate. Blood, 123 (5), pp. 611-612.

Rosenberg, P. S., Tamary, H. y Alter, B. P. (2011). How high are carrier frequencies of rare recessive syndromes? Contemporary estimates for Fanconi Anemia in the United States and Israel. American Journal of Medical Genetics Part A, 155 (8), pp. 1877-1883.

Rothbaum, R., Perrault, J., Vlachos, A., Cipolli, M., Alter, B. P., Burroughs, S. [...] y Rossi, T. (2002). ShwachmanDiamond syndrome: Report from an international conference. The Journal of Pediatrics, 141 (2), pp. 266-270.

Ruggero, D. y Shimamura, A. (2014). Marrow failure: a window into ribosome biology. Blood, 124 (18), pp. 27-84-2792.

Sans-Sabrafen, J., Besses Raebel, C. y Vives Corrons, J. L. (2006). Hematología clínica (5. ed.). Elsevier. 
Savage, S. A. (2013). Dyskeratosis Congenita. GeneReviews. [En línea]. Disponible en http://www.ncbi.nlm.nih. gov/books/NBK22301/

Shimamura, A. y Alter, B. P. (2010). Pathophysiology and management of inherited bone marrow failure syndromes. Blood Reviews, 24 (3), pp. 101-122.

Tolar, J., Adair, J. E., Antoniou, M., Bartholomae, C. C., Becker, P. S., Blazar, B. R. [...] y Thrasher, A. J. (2011). Stem Cell Gene Therapy for Fanconi Anemia: Report from the 1st International Fanconi Anemia Gene Therapy Working Group Meeting. Molecular Therapy, 19 (7), pp. 1193-1198.

Tremblay, J. P., Xiao, X., Aartsma-Rus, A., Barbas, C., Blau, H. M., Bogdanove, A. J. [...] y Gao, G. (2013). Translating the Genomics Revolution: The Need for an International Gene Therapy Consortium for Monogenic Diseases. Molecular Therapy, 21 (2), pp. 266-268.

Tsangaris, E., Klaassen, R., Fernández, C. V., Yanofsky, R., Shereck, E., Champagne, J. [...] y Dror, Y. (2011). Genetic analysis of inherited bone marrow failure syndromes from one prospective, comprehensive and populationbased cohort and identification of novel mutations. Journal of Medical Genetics, 48 (9), pp. 618-628.

Verlinsky, Y., Rechitsky, S., Schoolcraft, W., Strom, C. y Kuliev, A. (2001). Preimplantation diagnosis for Fanconi anemia combined with HLA matching. JAMA, 285 (24), pp. 3130-3133.

Vives Corrons, J. L. (2013). Why ENERCA? European Network for Rare and Congenital Anaemias. Genome Research \& Society, 10, pp. 33-37.

Vives Corrons, J. L. y Aguilar i Bascompte, J. L. (2014). Manual de técnicas de laboratorio en hematología (4.a ed.). Elsevier.

Vlachos, A., Rosenberg, P. S., Atsidaftos, E., Alter, B. P. y Lipton, J. M. (2012). The incidence of neoplasia in Diamond-Blackfan anemia: a report from the Diamond-Blackfan Anemia Registry. Blood, 119 (16), pp. 3815-3819.

Vulliamy, T., Marrone, A., Szydlo, R., Walne, A., Mason, P. J. y Dokal, I. (2004). Disease anticipation is associated with progressive telomere shortening in families with dyskeratosis congenita due to mutations in TERC. Nature Genetics, 36 (5), pp. 447-449.

Walne, A. J., Vulliamy, T., Kirwan, M., Plagnol, V. y Dokal, I. (2013). Constitutional mutations in RTEL1 cause severe dyskeratosis congenita. The American Journal of Human Genetics, 92 (3), pp. 448-453.

Wegman-Ostrosky, T. y Savage, S. A. (2017). The genomics of inherited bone marrow failure: from mechanism to the clinic. British Journal of Haematology, 177 (4), pp. 526-542.

World Health Organization (2011). Haemoglobin concentrations for the diagnosis of anaemia and assessment of severity. Vitamin and Mineral Nutrition Information System. [En línea]. Disponible en http://www.who.int/ vmnis/indicators/haemoglobin.pdf

Zanella, A., Fermo, E., Bianchi, P. y Valentini, G. (2005). Red cell pyruvate kinase deficiency: molecular and clinical aspects. British Journal of Haematology, 130 (1), pp. 11-25. 